\title{
Hydromechanical coupling concepts for mine slopes
}

\author{
TD Sullivan PSM, Australia
}

\begin{abstract}
In soil and rock environments, effective management of any excavation is dependent on an understanding of the slope movements and the factors that influence these. Slope movements cover a continuum from small deformations to collapse. These movements are nearly always of sufficient magnitude to affect the physical properties of the rock mass, the groundwater contained therein and the potential impacts from external loading events. Consequently, a thorough understanding of the mechanisms and the roles of stress, creep movements, instability, ground and surface water impacts at each stage of the movement process is fundamental for effective management and control of slopes.
\end{abstract}

This paper covers the theory and practice with excavated slopes in lower strength materials in some typical geotechnical settings focussed on the roles of ground movements, ground and surface water interaction and hydromechanical coupling. Wide experience has demonstrated there are common behavioural patterns associated with these typical geotechnical settings. The behavioural patterns comprise the processes, interactions and responses; which occur to various degrees throughout most stages of the life of an excavated slope.

The paper deals with soil and soft rock, footwalls and inclined layered or bedded sequences. However, the same concepts and ideas also apply to various extents to jointed hard rock and complex geological/geotechnical materials. The examples are based on large-scale monitored performance. The paper shows how the geotechnical and hydrogeological character of the materials leads to complex interactions between the various factors. The aim of the paper is to provide practical guidance for professionals working in the mine slope environment.

Keywords: hydromechanical coupling, mine slopes, pit slope movement, in situ stress, groundwater, transient groundwater pressures, geotechnical settings

\section{Introduction}

The theory and practice of hydromechanical coupling concerns the understanding of the interaction between soil and rock, the solid components of the earth, and the water contained therein. The theory component is quite straightforward and more fully explained in Sullivan (2007), Neuzil (2003) and Rutqvist \& Stephansson (2003). However, the practice is much more difficult to conceptualise and to use in engineering design and management. Groundwater behaviours can be very complex with large changes over time and with excavation. Therefore, it is sometimes difficult to get an accurate picture from simple monitoring systems and these may give contradictory or incorrect signals. There are also several practical challenges and difficulties, principal amongst these are:

- The complexity and heterogeneity of most mine sites.

- On many mine sites, groundwater and geotechnical engineering are somewhat separated and often not well integrated.

- In many instances, there is insufficient monitoring data in the right locations to allow holistic conclusions to be drawn.

- Many professionals only experience a narrow range of geotechnical settings. 
This leads to inherent difficulties in understanding the magnitude, significance and relevance of the hydromechanical coupling effects when they do occur. However, probably the most fundamental hurdle to an adequate understanding of hydromechanical coupling effects is that all excavated slopes are in effect new slopes (Sullivan 2007). The environment does not change pre- and post-excavation but a new slope is being constructed and it will behave in a certain manner and then interact with the environment in certain ways. How that impacts on the newly excavated slope and the resultant slope performance depends on the type of geotechnical setting. In this paper, the geotechnical setting is the combination of in situ stress, rock mass modulus, rock mass geotechnical character, defect orientations and patterns, and defect characteristics. This paper presents the concepts of understanding of hydromechanical coupling effects in some different geotechnical settings that have been developed over many decades of experience.

\section{$2 \quad$ Hydromechanical coupling and mine slopes}

\subsection{Introduction}

There is extensive coverage of the history of development of the theory of hydromechanical coupling and the empirical evidence supporting the concepts in Neuzil (2003) and Rutqvist \& Stephansson (2003). These papers deal mainly with porous media flow, geological processes deep within the earth's crust, deep experience from the oil industry, deep well injection and deep-seated hydromechanical coupling mechanisms associated with induced seismic activity. Coverage of other areas is limited to the available published areas of investigation and research. Hydromechanical coupling in soils and clay slopes is covered by Alonso et al. (2003) but this is only for one geotechnical material and is in a very shallow region of the earth.

There is little information dealing directly with the deformation, the response of mine slopes and hydromechanical coupling. For example, Beale \& Read (2013) deal only briefly with hydromechanical coupling in mining and consider "The most common consideration of hydromechanical coupling in mining environments is the response to lithostatic unloading".

However, this is too narrow a consideration and in many mine slopes, hydromechanical coupling is linked directly with considerations of the Factors of Safety for design and management of both short- and long-term slope performance.

The materials encountered in open cut mines cover an extremely wide range and lie in a relatively near-surface environment, compared to the higher stress environments mainly covered in Neuzil (2003) and Rutqvist \& Stephansson (2003). Mines are developed in everything from soils to the hardest rocks, mixed soil and rock environments, extensively fractured and altered materials, and all the principal rock types. This presents a complex and challenging environment in which to understand and predict responses of solid materials, the waters contained therein, and the interaction with the environment.

The first paper dealing directly with hydromechanical coupling in the mine slope environment was Sullivan (2007). This is a companion paper to that earlier publication and focusses on the hydromechanical responses in different geotechnical settings.

\subsection{Mine slopes}

All excavated slopes move. Some mine slopes only show elastic movements, others undergo long-term creep and some progress to failure. It is very rare for any mine not to have at least one significant slope failure. Failures are just a normal part of mining. Defect apertures change as a mine slope is excavated. As mine slopes progress from elastic movements, due to unloading, through the complex movements leading up to failure, there are substantive changes to defect apertures and hydraulic connections and conductivities. This is particularly important for consideration of the groundwater responses, the impacts of rainfall runoff loading events and transient pore pressures. 


\subsection{Five basic fundamental concepts for understanding hydromechanical coupling and mine slopes}

Notwithstanding the previous discussion and the complexity of the mine slope environments, it is the author's experience over many decades of investigation in a very wide range of different mine slope settings, that certain basic concepts are fundamental for building an effective understanding.

Firstly, it is fundamentally important to understand that "...all geotechnical materials are part of one continuous spectrum..." and "...one continuous science extending from soft soils to hard rocks. All geotechnical materials behave according to the same engineering principles, with obvious differences a function of degree rather than fundamental nature" (Johnston 1991).

The second concept is that mine slopes need to be differentiated from natural slopes because they are new slopes, where:

- In most cases, the stresses and the physical dimensions of the slopes are changing over the mine life.

- These recently excavated slopes will experience new environmental influences.

- The responses of the mine slope to those influences will change over the life of the mine.

- Hence accurate predictions ahead of mining are fraught with difficulties.

The third concept is the understanding that once a mine slope starts moving, either episodically or continuously, then the likelihood of hydromechanical coupling increases. The hydromechanical coupling may be positive or negative and nearly always changes over the life span of the movements. The future likelihood of a hydromechanical coupling effect and the future stability cannot be accurately predicted using:

- The rate of displacement, as even the very smallest of creep rates can be significant.

- The total magnitude of the movement.

- The total time over which the slope has been moving.

The fourth concept relates to considerations of Factors of Safety, which need to be largely discarded for some slopes. Progressive failure in some materials is the main stability consideration. Irrespective of the initial calculations of Factor of Safety, creep movements are inevitable, eventually leading to adverse hydromechanical coupling, which means the slope will have a high probability of failure at sometime in the future.

This leads to the final aspect: pit slope management. In many instances, the success of the mining operation is not about how well the slope was designed at the start or the Factor of Safety chosen for design but rather how well the critical issues are understood and managed throughout the mine life.

\subsection{Conclusion}

It is the basic premise of this paper that the actual response of the rock mass to excavation of a mine slope is firstly dependent on the geotechnical setting, which may be classified using a simple combination of mine type and geotechnical characteristics. The art in mine slope design is the ability to firstly recognise the important geotechnical factors at any location in the earth and then to combine these factors into a geotechnical setting (Sullivan 2010). The likelihood of occurrence of a hydromechanical coupling response and its potential impacts are then more predictable.

\section{$3 \quad$ Hydromechanical coupling theory and empirical evidence}

\subsection{Introduction}

Hydromechanical coupling is the physical interaction between hydraulic and mechanical processes in the earth. All geological materials, both soils and rocks, contain pores and defects, which are deformable to 
various extents depending on their properties. When these pores and defects are filled with water and loaded or unloaded, then hydromechanical coupling occurs. Under an increased load (increased stress), the mass is compressed (both solid and liquid) to a smaller volume. When a load increase is applied quickly, this will tend to compress the water in the pores and defects and increase fluid pressure because there is insufficient time for the water to drain. If the load is applied slowly, there is enough time for the water pressure to decrease. These are the undrained and drained hydromechanical coupling responses of the mass. Similarly, if the water pressure in the pores and defects is reduced then the mass will compress and subsidence occurs, which is also hydromechanical coupling.

Soil and rock masses are composed of both the intact mineral grains or intact rock and pores or defects. For the purposes of this paper, changes to the solid component of the mass are not material.

The key elements of direct relevance for understanding of hydromechanical coupling in the mine slope environment are:

- The behaviour of soil and rock defects under changes in normal and in shear stress.

- The impacts of these changes on defect apertures and hydraulic conductivity (permeability).

- The sensitivity of defect apertures to these changes.

- The hydraulic characteristics of different soil and rock masses.

- The role of stresses and stress changes during mining.

- The relationship between hydraulic conductivity and depth.

These aspects are discussed in the following sections.

\subsection{Defects}

\subsubsection{Introduction}

Defects (geological discontinuities) in soil and rock masses follow a geological hierarchy: from the first order or major defects (which have large continuity and are usually faults or shears) to the third or fourth order minor defects (which may be discontinuous tension joints) (Figure 1). Defect aperture, how it varies with defect type, defect surface characteristics and how aperture changes under changing stresses and deformations is a key part of hydromechanical coupling.

It is well accepted that defects are deformable and defects will respond in an elastic manner to changes in normal and shear stresses. The magnitude of the opening and closing of the defect under changes in these stresses is given by the defect normal stiffness and defect shear stiffness, respectively. The lower the strength and modulus of elasticity of the material forming or close to the defect walls, then generally the lower the normal and shear stiffness of the defects.

The fundamental form and hydraulic characteristics of defects is also important. All defects have an irregular surface shape. The two sides of the defect rarely match and are only partially in contact. Water flow takes place in the voids between the two defect surfaces, which, because of the form of the defect surfaces is highly channelised and the channels are tortuous in shape. Most experimental data on fluid flow in defects has been in relation to normal stress and there is more limited data on the behaviour under shear stress (Rutqvist \& Stephansson 2003). 


\subsubsection{Defect aperture}

Early studies on parallel plate flow, Snow (1968) and Louis \& Maini (1970), showed that defect flow could be described by the following equation:

$$
K=\frac{g e^{3}}{12 b v}
$$

where:

$$
\begin{aligned}
& K=\text { hydraulic conductivity. } \\
& E=\text { joint aperture. } \\
& B=\text { joint spacing. } \\
& V=\text { viscosity of water. }
\end{aligned}
$$

This is referred to as the cubic law. The equation applies to smooth parallel plates and was partly validated by testing on artificial tension defects in samples of granite and marble by Witherspoon et al. (1980) who developed a modified cubic law. Witherspoon et al. also distinguished between the physical aperture and the hydraulic aperture of defects, which relates to the physical characteristics of the defect surfaces and defect infill.

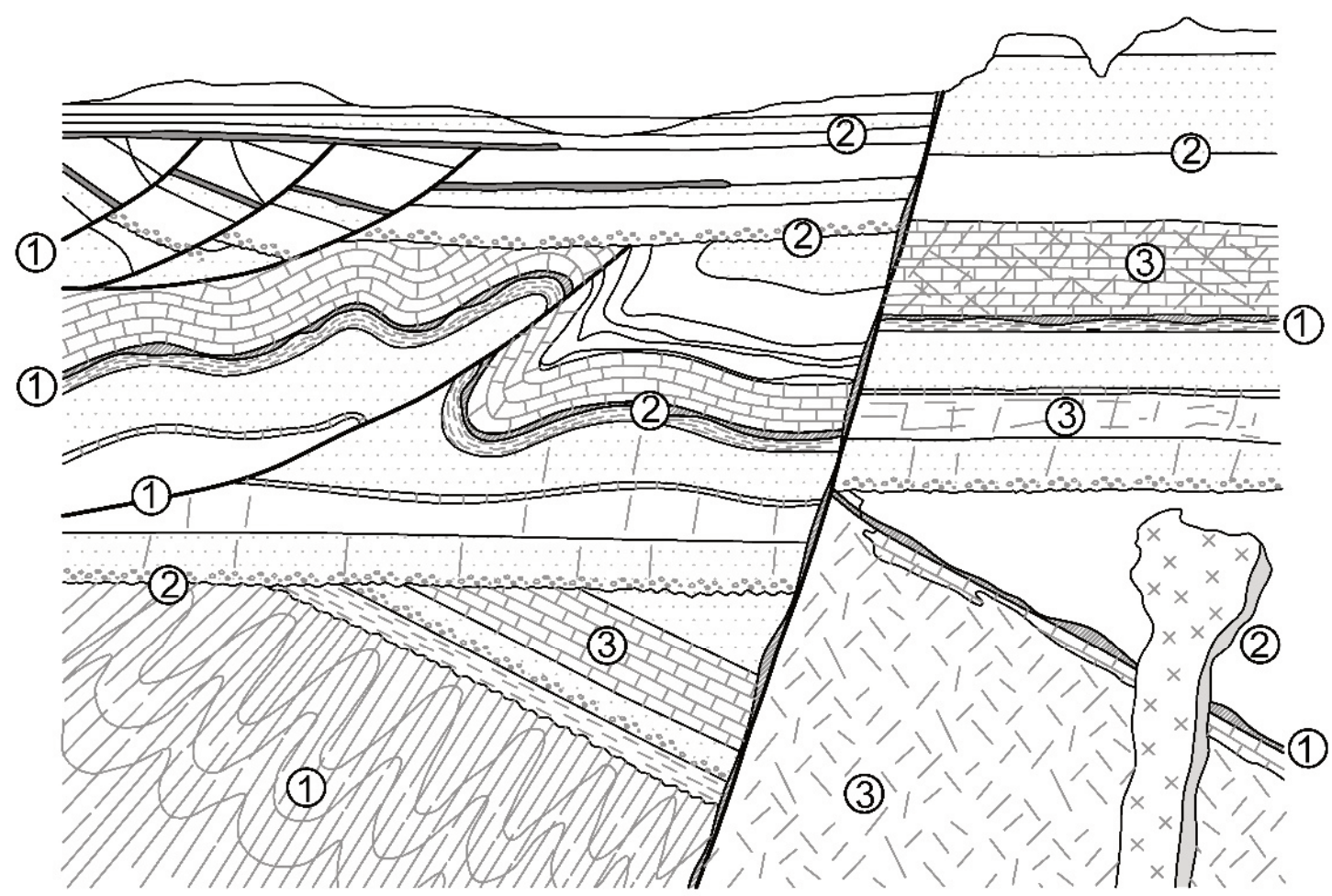

(1)

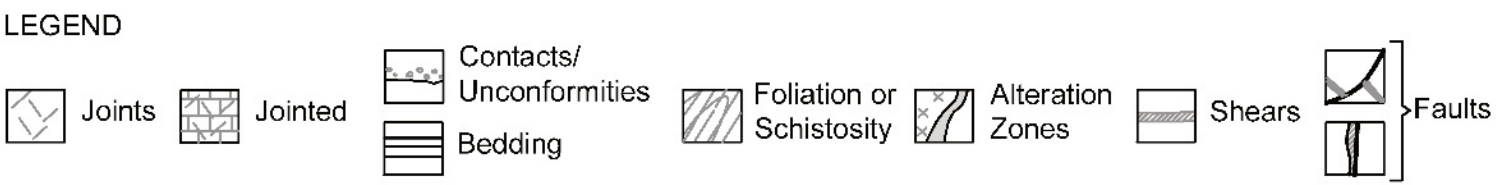

Hierarchy of Geological Defects
(1) First Order
(2) Second Order
(3) Third Order

Figure 1 Illustration of the hierarchy of geological defects; first, second and third order (Sullivan 2013) 
There has been conflicting laboratory evidence regarding the validity of the cubic law and the effects of contact area for fluid flow in rock defects. However, despite this, a careful review by Boitnott (discussed in Rutquist \& Stephansson 2003) of the conflicting evidence around the cubic law found that the predictions using the cubic law commonly holds for a wide variety of defects. In many cases, the modified cubic law breaks down as defect closure increases, however, this tends to occur only when the hydraulic aperture is less than about $50 \mu \mathrm{m}$. This is a very fine aperture and probably not significant within the context of the discussions in this paper.

Hence, despite the uncertainty around the cubic law, the hydraulic conductivity and response of defects is clearly very sensitive to defect aperture and something approximating the cubic law gives a good representation across the range of stress levels encountered in general engineering practice for mine slopes. Understanding the importance of defect apertures, their characteristics in different types of defects and rock masses, the changes that occur to those apertures under the changing stress conditions, and the movements that occur as mine slopes are excavated, is important for evaluating hydromechanical coupling responses in mine slopes.

\subsubsection{Behaviour under changes in normal stress}

Under increasing normal stress, the deformation across a defect is non-linear (Figure 2(a)). The rate of defect closure is highest at lower values of normal stress and the defect stiffness increases as the normal stress increases. In soils and lower strength rocks the impact of changes in normal stress on the hydraulic conductivity of defects are much more significant.

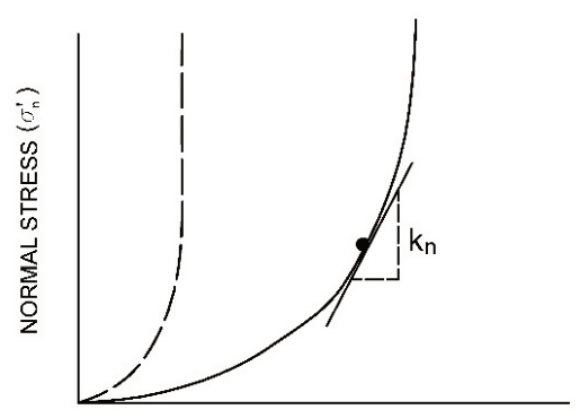

DEFECT CLOSURE $(\Delta \varepsilon n)$

(a)

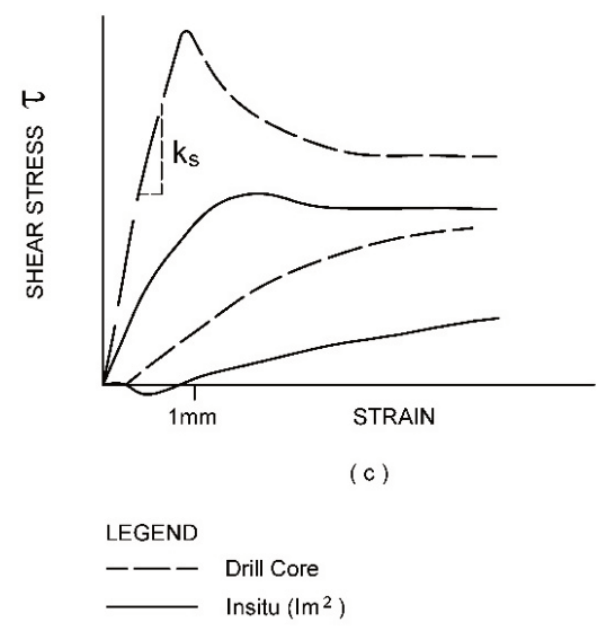

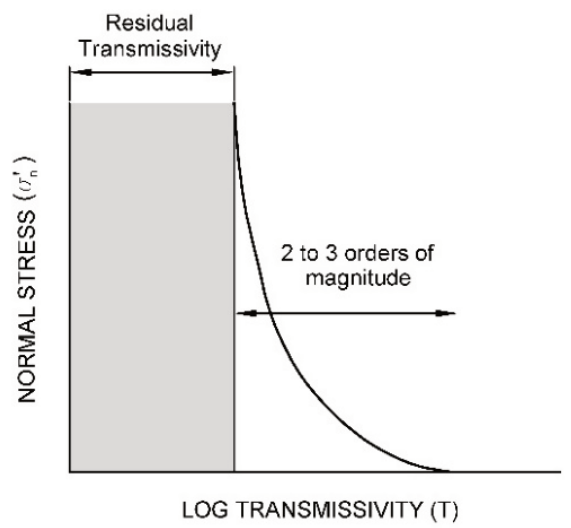

(b)

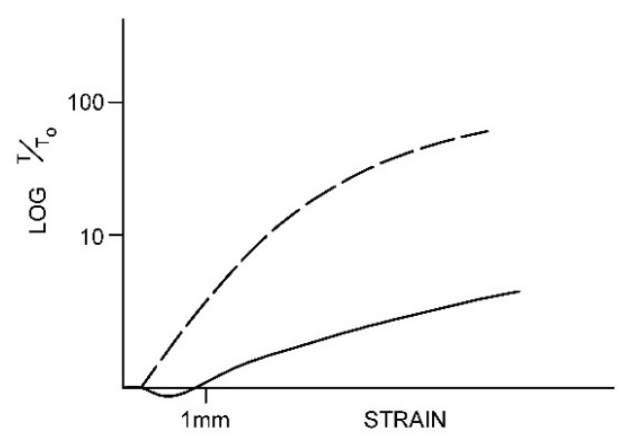

(d)

Figure 2 Typical deformation and hydromechanical response for a defect under normal ( $a$ and $b$ ) and shear stress $(c$ and $d) . T=$ transmissivity, $k n=$ fracture normal stiffness, $k s=$ fracture shear stiffness (Sullivan 2007 and after Rutqvist \& Stephansson 2003) 
Probably one of the most famous examples of hydromechanical coupling behaviour under normal stress is the failure of Malpasset Dam in 1959. In this example, closure of defects in the dam foundations under the loading of a concrete arch dam led to a reduction in hydraulic conductivity of two orders of magnitude (Londe 1987).

Experiments typically show a decrease in defect hydraulic conductivity (or transmissivity) with increased normal stress, which can be two or three orders of magnitude (Figure 2(b)). However, there is an apparent residual conductivity, even at high stress. This indicates that at high-stress levels, water flow is controlled by tube-like channels. These channels would have a structure and shape (aspect ratio) that means they cannot be readily closed.

There is also some limited experimental data to indicate a size effect with increasing closure associated with increasing sample size (Figures 2(a) and (c)). Neuzil \& Tracy (1981) attributed this size effect to sample size, with fewer higher flow channels contained in a smaller sample, which intuitively appears correct. That experimental data also showed the effective aperture could not be decreased below $30 \mu \mathrm{m}$ even at a normal stress of $7 \mathrm{MPa}$.

The results from some hydraulic jacking tests (Rutqvist et al. 1997) gives an added understanding of defect and rock mass responses under positive changes in normal stress. The tests showed that the sensitivity of defects is strongly dependent on the initial hydraulic permeability, where the permeability of the most conductive defects is relatively insensitive to injection pressure and the hydraulic conductivity of the least conductive defects can be strongly dependent on the injection pressure. Borehole televiewer imaging showed the most conductive defects appear to be open and incompletely cemented. Again, indicating flow channels within the defect that are 'locked open' either by shear displacement and or mineral cementation.

Excavation of mine slopes can often result in large reductions in normal stresses. Depending on the defect characteristics and orientations, this would lead to significant defect opening (Figure 2(a)) and significant increases in transmissivity (Figure 2(b)).

Burland et al. (1977) describe the results of a large-scale trial excavation undertaken in an Oxford Clay pit. Although measurement of hydromechanical coupling was not the aim, the piezometer hydrographs clearly show direct hydromechanical coupling responses. Sequential mining of parallel slices from a steep pit face reduced the normal stress and caused large groundwater reductions.

\subsubsection{Behaviour under shear displacement}

Defect shear behaviour has been extensively studied and developed in the field of rock mechanics for more than 50 years. In that regard, the existence of scale effects has been proven. Figure 2(c) shows a typical shear stress displacement of a clean, rough, dilatant defect under constant normal stress. It is characterised by a rapid increase in shear stress up to a peak, followed by a reduction back to a residual stress. The lower curves in Figure 2(c) show the defect dilation accompanying that shearing. Initially, there is an elastic deformation of the defect with minimal dilation. This is followed by the onset of rapid dilation as asperities begin to ride over each other. The rate of dilation increases and reaches a maximum at the peak stress. The peak shear strength depends on normal stress, which means the dilation behaviour may also be slightly different under higher than normal stresses.

Testing of the hydraulic properties of defects under shear is difficult and hence, there is limited test data available. One set of testing (Makurat et al. 1990) concluded that whether the conductivity increases or decreases with shear depends on both the joint and rock properties, and the nature of the stress applied. Gouge development in the defect voids caused decreases in hydraulic conductivity and tended to block flow paths. However, other tests on granite showed the hydraulic conductivity starts to increase after very small shear displacements and then increases rapidly by about one to two orders of magnitude up to $5 \mathrm{~mm}$ shear (Esaki et al. 1999; Olsson \& Barton 2001) (Figure 2(d)). Because of the shearing of asperities and the development of gouge, there can be a significant difference between the dilation and the increase in the effective hydraulic aperture of the defects. Thus, the aperture of a defect formed under shear may be 
substantially different to the effective hydraulic aperture. Any prediction of the changes in hydraulic properties under shear displacements needs to carefully consider the geotechnical properties of the defect.

In mine slope engineering and, in particular, dealing with the continuous, lower strength defects, such as clay seams, bedding plane shears, gouge filled defects, it is the author's experience that significant shear displacement on these types of structures generally does not result in large increases in hydraulic conductivity along the defect plane. Rather the displacements on these defects results in two effects:

1. The structure becomes a hydrogeological barrier for flow normal to the defect.

2. Higher hydraulic conductivities develop in the lower order defects surrounding and/or intersecting the low strength defect, resulting in a zone of higher conductivity subparallel to the defect plane.

\subsubsection{Defect behaviour and mine slopes}

The interpretation of these results in relation to hydromechanical coupling and mine slopes is:

1. The increase in aperture and hydraulic conductivity of defects is generally larger for changes in normal stress than for changes in shear stress.

2. In a hard rock environment, clean joints will generally undergo large increases in aperture and hydraulic conductivity under both changes in normal and shear stresses.

3. As the rock mass modulus and/or rock strength decreases, the degree of aperture and hydraulic conductivity increase under shear displacement, becoming progressively less.

4. In general, shear displacement on first order defects, particularly those with lower strength, alteration and or clay infill, will result in decreases in hydraulic conductivity normal to the defect.

5. However, this same shear displacement on these first order defects will often result in significant increases in aperture and hydraulic conductivity in the second and third order defects on either side.

\subsection{Characteristics of soil and rock masses}

\subsubsection{Introduction}

This section describes some of the hydraulic characteristics of soil and rock masses. This is clearly a complex situation to describe adequately. The in situ, undisturbed conditions are related, in part, to the current distribution of in situ stress and permeability in the earth's crust, which are, in turn, the result of past and ongoing geological processes. However, in an engineering timeframe, this may be taken as a quasi-static condition.

Knowledge of the in situ hydraulic characteristics and the factors influencing them provides an important basis for understanding the influence of changing stresses. Some important factors include:

- The correlation between in situ stress and hydraulic conductivity.

- The decrease in hydraulic conductivity with depth (stress).

- Strong anisotropy of principal stresses can result in anisotropy in the hydraulic conductivity.

Figure 3 is a schematic representation of a heterogeneous rock mass forming a pit slope. This figure illustrates deformations, both shear and normal, for rock discontinuities and the rock mass. In saturated rock masses, deformation can occur as a result of a change in the stresses or a change in the pore fluid pressures. The rock mass is saturated (below the groundwater table) and hence, it is evident that any deformations in the rock mass will result in a change in the pore fluid pressure and a change in both the hydraulic conductivity and storage. Although all defects are affected by the changes in stress conditions, it is evident that the first and second order defects show the largest changes (Figures 3 and 4). 


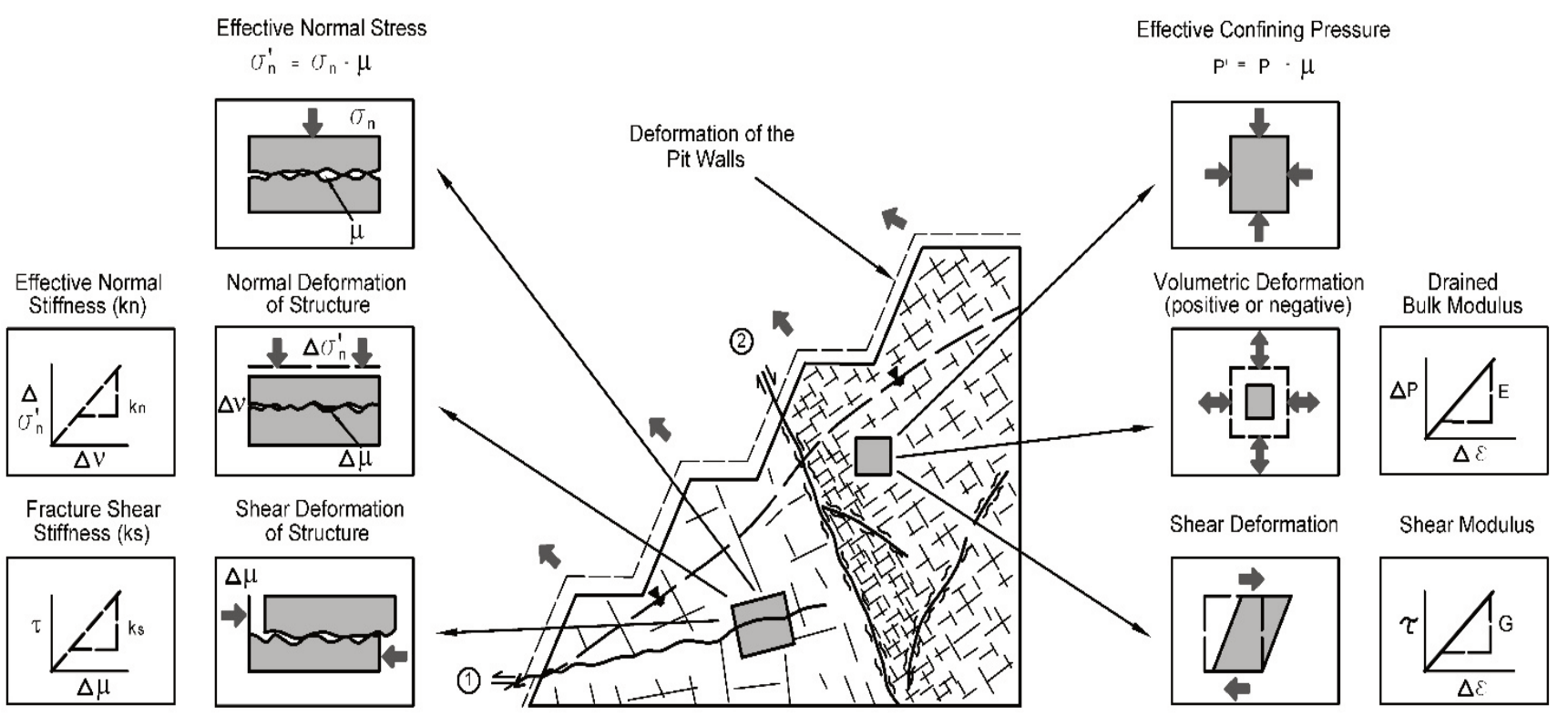

Figure 3 Schematic representations of hydromechanical coupling processes in a rock mass. Where $\sigma_{n}^{\prime}$ is effective normal stress, $v$ is normal displacement, $\tau$ is shear stress, $\mu$ is shear displacement, $\varepsilon$ is strain, $E$ is modulus, and $G$ is shear modulus (Sullivan 2007). Refer to Figure 4 for examples

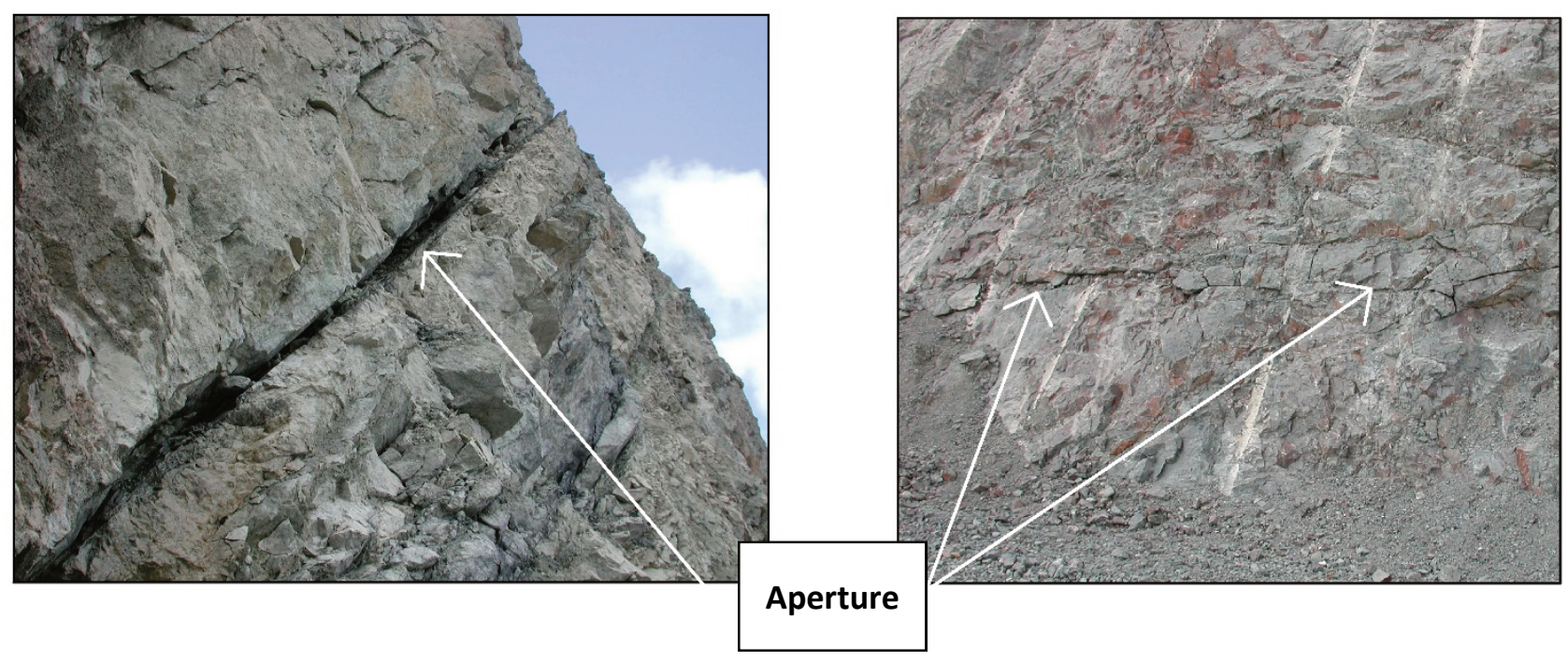

(a)

(b)

Figure 4 Dilation on structures in a pit wall (for locations, see Figure 3). (a) Dilation due to toppling (block rotation); (b) Dilation due to shear on an undulating irregular sub-horizontal structure. Refer to points marked 2 and 1 in Figure 3. Note the aperture and thus, resultant hydraulic conductivity, is a function of both the type of displacement and the orientation of the structure relative to the slope or principle stresses, with example (a) clearly larger and more consistent than (b)

\subsubsection{Empirical models of fractured rock}

Rock masses contain defects of various scales, from small discontinuous joints to major faults and fault zones at kilometre scale (Figure 1). Therefore, both the mechanical and hydraulic properties are typically strongly heterogeneous, particularly at the mine slope scale (Figure 5). 


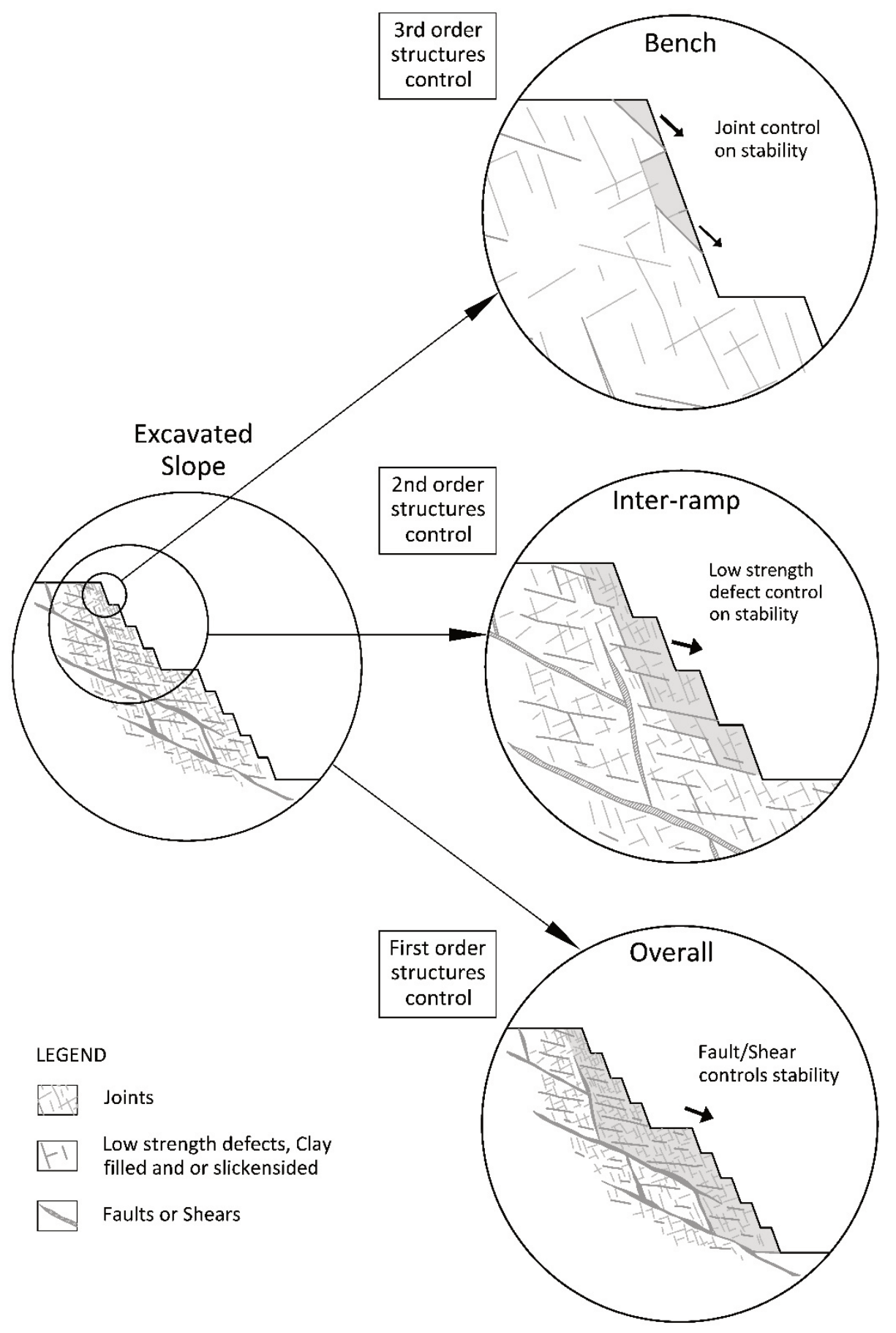

Figure 5 Illustration of first, second and third order defects relative to mine slope scales (Sullivan 2013)

Figure 6 shows a conceptual model for the U.S. Geological Survey's fractured rock research site near Mirror Lake, New Hampshire (National Research Council 1996). The investigations showed the rock mass consists of a small number of defects with high hydraulic conductivity within a network of much lower conductivity defects. The high conductivity defects are grouped into sub-horizontal, tabular-shaped forms, several meters thick and 10 to $40 \mathrm{~m}$ in length. It should be noted that this investigation is at a shallow depth in glaciated terrain and hence, the reduction in the normal stress due to the glaciation has probably contributed to the increases in hydraulic conductivity in the sub-horizontal direction. This pattern of a few higher-conductivity defects connected in groups has been observed at many igneous and volcanic rock mass sites (Rutquist \& Stephansson 2003). 


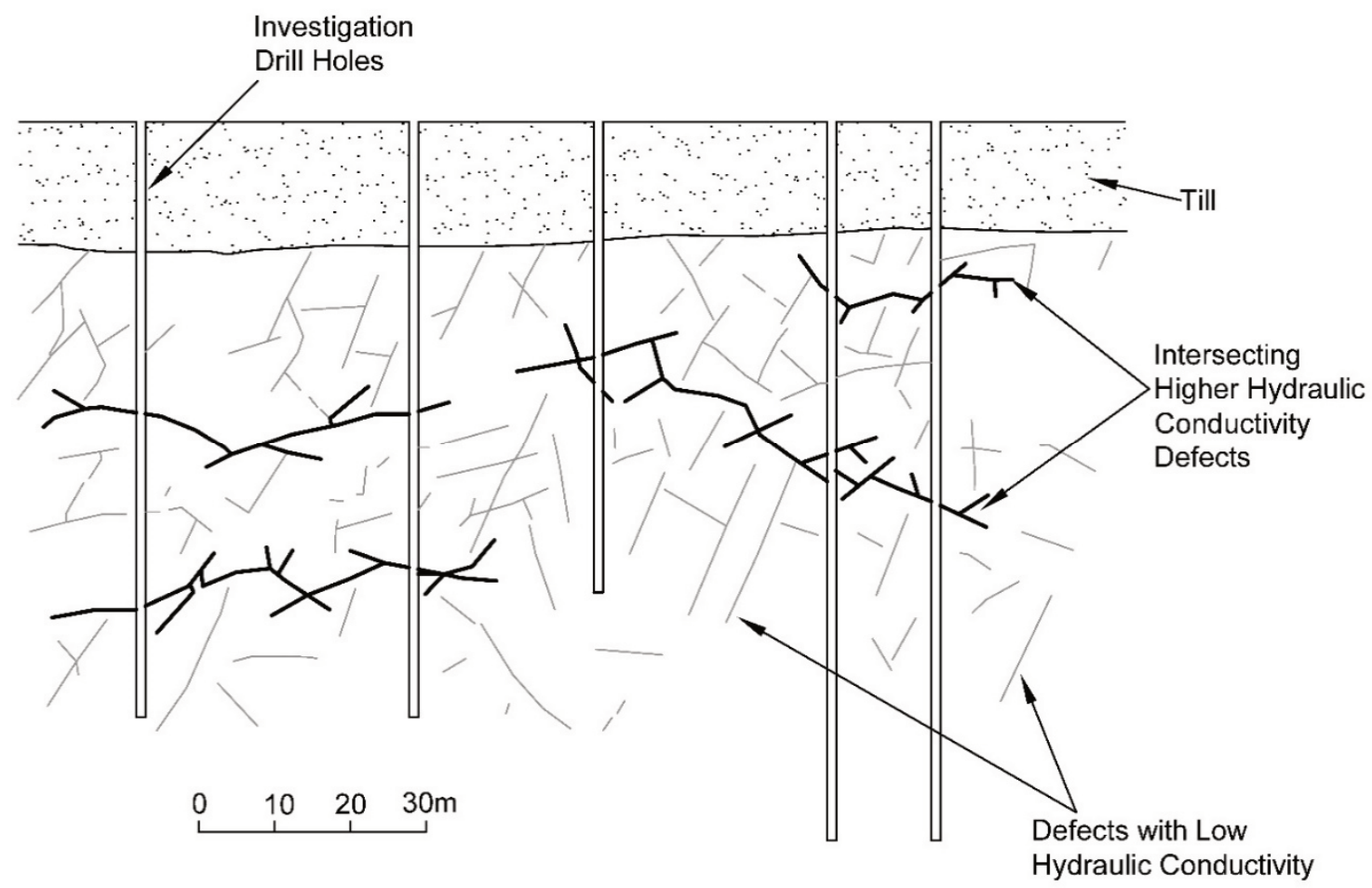

Figure 6 A cross-section showing the conceptual model of rock mass conductivity (after Rutquist \& Stephansson 2003)

Investigations at a nuclear waste disposal site identified four main characteristic higher-conductivity defect features within the rock mass (Olsson 1992):

1. Individual, larger aperture, open-flow channels along a major defect.

2. Sub-horizontal tension joints with evenly distributed aperture and flow.

3. Flow concentrated where a steeply dipping defect terminates against a sub-horizontal defect.

4. Concentrated flow at defect intersections.

\subsubsection{Relationship between hydraulic conductivity and depth}

Figure 7(a) presents a profile of hydraulic conductivity from packer testing in a granitic rock mass in Sweden (Wladis et al. 1997). Despite the very wide range of hydraulic conductivities, there is a general decrease in conductivity with depth, which is most pronounced in the upper 100 to $300 \mathrm{~m}$. This effect could be related, in part, to stress relief caused by erosion and isostatic rebound after glaciation. However, it is considered that the effect is mainly due to the non-linear relationship between normal stress and aperture of joints (Figures 4(a) and (b)).

Similar decreases in hydraulic aperture with depth have also been observed elsewhere (Snow 1968). That testing showed the inferred aperture decreases from about $200 \mu \mathrm{m}$ at the ground surface to about $50 \mu \mathrm{m}$ at $60 \mathrm{~m}$ depth. This relationship would tend to be reversed as a mine slope is excavated and the normal stress reduces (Figure 2(a)).

The maximum hydraulic conductivities on the right side of Figure 7(a) are interpreted to represent the situation where there is either:

- At least one highly conductive defect, which is connected to a larger network of other conducting defects.

- Fault or shear zones where large movements have caused shear dislocation on the plane itself and with development of oblique defects in the surrounding rock mass (Figure 8). 
The minimum hydraulic conductivities on the left side of Figure $7(a)$ are interpreted to represent intact rock conductivities.

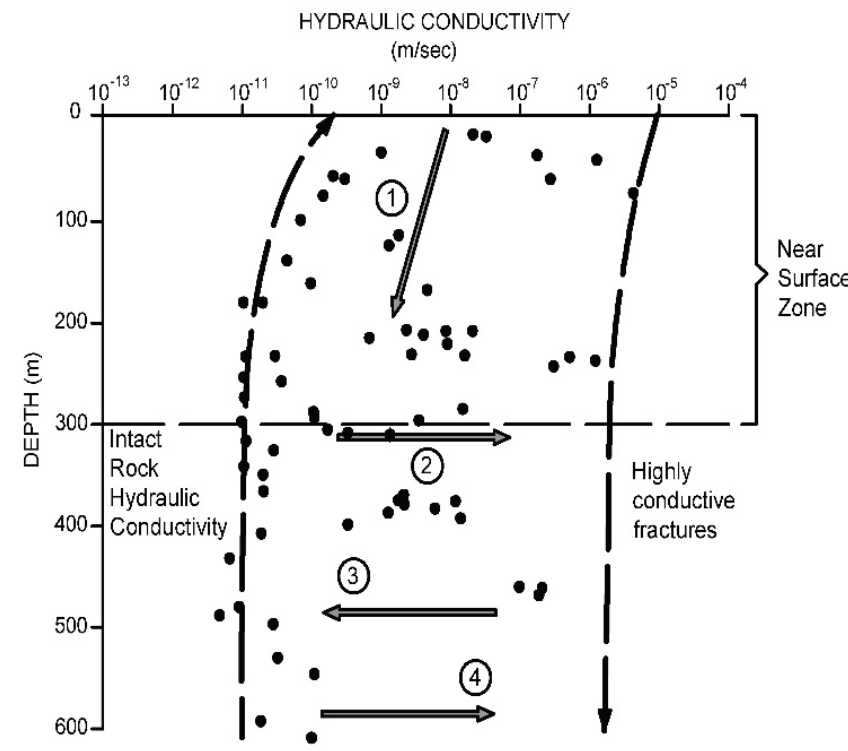

(a)

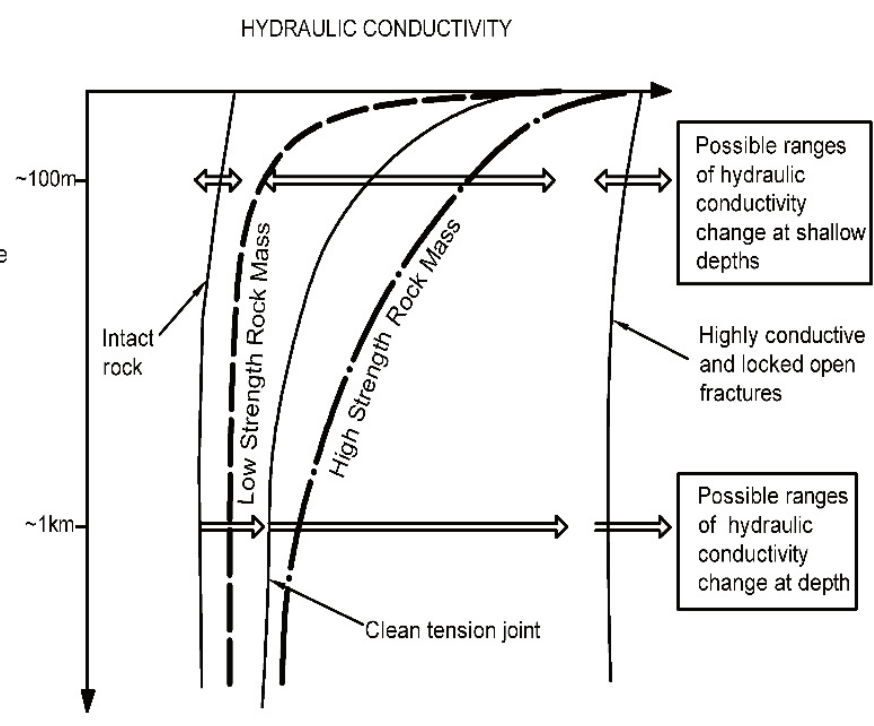

(b)

Figure 7 Relationship between hydraulic conductivity and depth. Two zones are indicated as shallow ( 0 to $300 \mathrm{~m}$ ) and deep. (a) There is a reduction in hydraulic conductivity in the near surface zone due to increasing stress (1), shear displacement generally tends to increase hydraulic conductivity (2), and both precipitation and dissolution of minerals at depth may either increase or decrease hydraulic conductivity ( 3 and 4); (b) The general depth hydraulic conductivity relationship for a low and high strength rock mass (after Sullivan 2007; Rutqvist \& Stephansson 2003)

\subsubsection{Correlation between anisotropic in situ stress and hydraulic conductivity}

The data on the relationship between in situ stress and hydraulic conductivity is limited or anecdotal (see the case study in Section 5). One study at $250 \mathrm{~m}$ depth in a granitic rock mass with an in situ stress anisotropy of 4.3 times showed a hydraulic conductivity anisotropy of three times (Carlsson \& Olsson 1979). Other studies of this relationship have mainly been at very great depth and associated with oil field development. Not surprisingly, given the magnitude of the in situ stress at kilometres depth, the results were inconclusive.

However, as noted in the Section 3.3.3, given the depth dependency of hydraulic conductivity in the upper 100 to $300 \mathrm{~m}$, it would be reasonable to assume that some stress-induced hydraulic conductivity anisotropy could occur within this zone.

\subsubsection{Excavation-induced hydraulic conductivity changes}

Any experienced practitioner would have encountered abundant direct observational evidence of induced apertures resulting from the mine excavation process. These apertures could have resulted from several causes, which, in order from largest to smallest influence, include blasting, digging and stress relief. However, detailed testing of excavation-induced hydraulic conductivity changes is largely limited to underground excavations associated with nuclear developments. Wyllie \& Mah (2004) reported an 18-fold increase in hydraulic conductivity associated with a $170 \mathrm{~m}$ deep excavation in granite for the Three Gorges Dam project in China. 


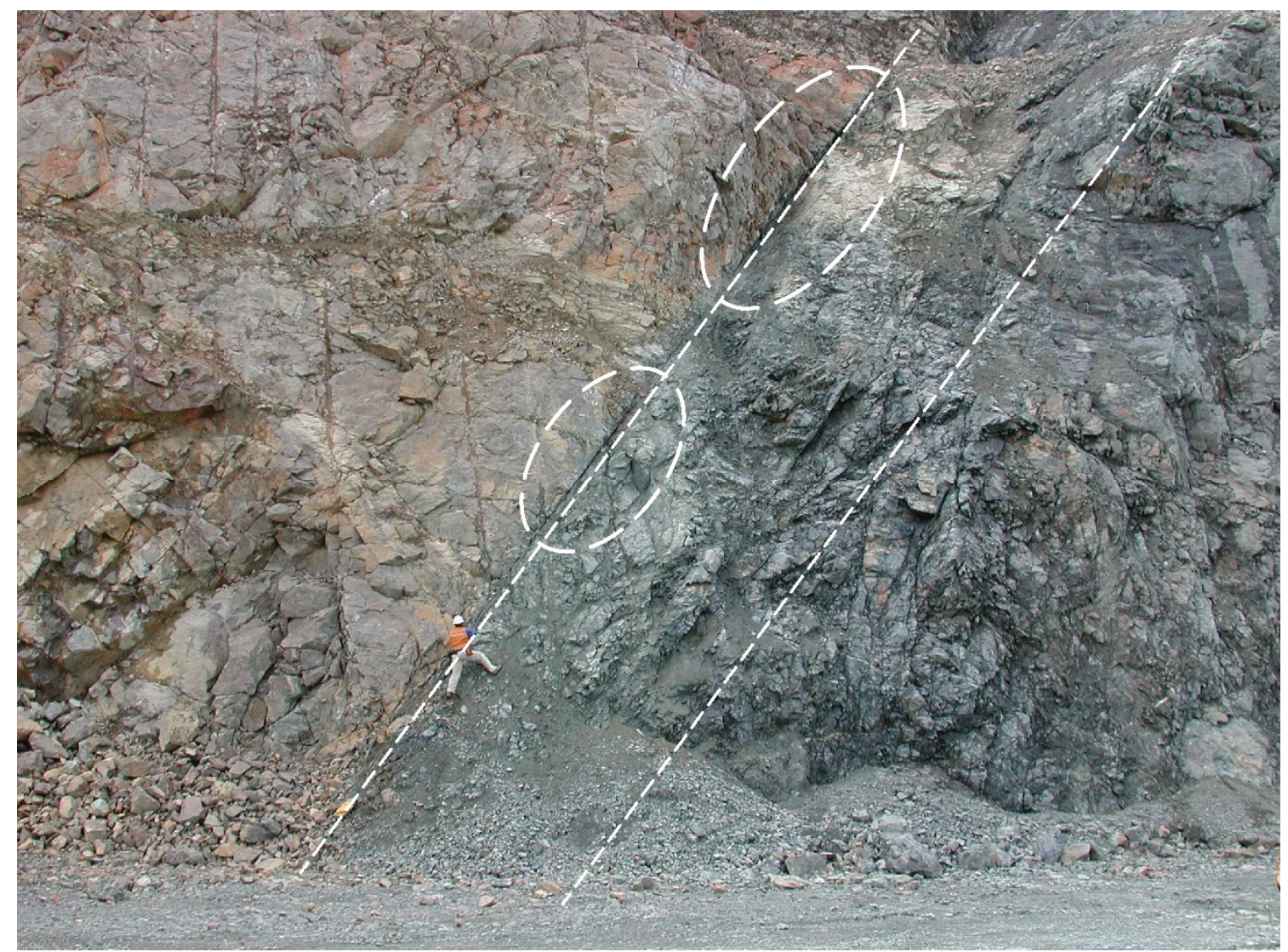

Figure 8 Major thrust fault zone offsetting igneous rock mass (right side) against a volcanic rock mass. Note the extensive development of secondary defects in the volcanic rock mass. Also note zones of increased aperture along the fault plane (dashed circles)

In mine slope engineering, it has become common to use the ' $D$ ' factor in rock mass strength estimates to account for damage to the rock by blasting (Hoek \& Brown 2018). This damage factor is to account for increased aperture of natural defects, new blast-induced cracks, shear dislocation along natural and induced fractures, and increased interconnection between natural and induced fractures. While the effect of blast-induced deformations on hydraulic properties of the rock mass can be quite substantial, there is no testing of the hydraulic properties of this zone.

Of course, if a mine slope is experiencing creep movements, then the defect apertures are not fixed and will be progressively increasing. In this case, the hydraulic conductivity is probably changing by orders of magnitude.

\subsection{Empirical observations}

Based on experience and available data, a few general observations are possible. Firstly, some rock masses are more sensitive to stress changes than others, for example:

- Rocks that contain flat and semi-continuous defects, such as shale and granite.

- Sedimentary rocks containing bedding plane shears.

- Rocks containing large-scale, first and second order, defects.

- Sheared and faulted rock masses.

- Rock masses with closely spaced intersecting defects.

The principal characteristic of these examples are either low strength and low modulus and/or low strength continuous defects; all of which would tend to enhance excavation related movements and lead to some anisotropy in the slope movements. 
Figure 4 illustrates the behaviour of two second order defects under a reduction in normal stress (Figure 4(a)), and under shear displacement (Figure 4(b)). The character of the aperture formed in each case is substantially different. Under a decrease in normal stress, there has been the formation of a consistent, wide aperture. In contrast, under shear displacement, the resultant aperture is irregular and variable. However, if the slope has been moving, then over time, orientations subparallel to the mine slope can become the most important (Figure 5). This is because movements tend to concentrate on defects in these orientations. This results in other lower order defects lying above the plane developing increased apertures.

Many field experiments have shown that, in general, major defects with a large initial hydraulic conductivity are less sensitive to changes in effective normal stress than defects with a smaller initial hydraulic conductivity (Rutquist \& Stephansson 2003). This is because the hydraulic conductivity is sensitive to the effects of defect infill. For example, the infill may completely block flow in a defect, while hard mineral infill may lock the defect open, allowing large flow channels between rock bridges in the defect plane. The evidence supporting this is from borehole tests that show large, open-flow channels exist at depths of several thousand metres. These fractures are so conductive that they are likely to be locked open by previous large shear displacement and or hard mineral infills. These highly-permeable defects will tend to be insensitive to stress changes because they have a high normal and shear stiffness.

The sensitivity of the hydraulic conductivity to stress changes depends on both the initial hydraulic properties and the initial physical and mechanical properties of the defect, including:

- The defect continuity.

- The defect orientations.

- The initial defect hydraulic conductivity.

- The interconnectivity of the conducting defect network.

- The defect normal stiffness.

- Defect surface characteristics.

- The defect shear strength.

Defects with large initial aperture are also likely to be more continuous and thus, for a given shear displacement, do not dilate as much as smaller fractures (Figure 8). Defects with a large initial aperture are also likely to have already been sheared past their peak shear strengths, which means further shearing will result in only small changes in hydraulic conductivity. Therefore, they are likely to be less sensitive to shear displacements.

At the other extreme are defects at shallow depth, which are partially infilled with soft minerals, have low normal stiffness, and a small initial hydraulic aperture because the fracture surfaces are coated with mineral filling. In the mine slope environment, these defects are less sensitive to changes in normal and shear stresses. Figure $7(b)$ illustrates the depth hydraulic conductivity relationship for two typical rock masses, a low strength rock mass and a high strength rock mass.

\section{$4 \quad$ Typical mine slope hydromechanical coupling process}

Figure 5 shows the relationship of mine slopes of various scales with first, second and third order defects. The relationships in this figure may be used conceptually to predict the effects of the stress changes resulting from the unloading due to mine excavation on the defects at each slope scale. At the bench scale, excavation is expected to result in minor impacts on the third order defects. At the inter-ramp scale, some movement and dilation of the sub-vertical structures dipping parallel to the slope may be anticipated, which may also be accompanied by minor shear on the structures dipping into the pit. Although at both scales, the potential for adverse hydromechanical coupling responses in the rock mass are inferred to be minor. However, at the overall slope scale, there is a high potential for an adverse hydromechanical coupling impact as the slope is mined. The initial coupling response to rainfall runoff would probably commence before the bottom four benches are mined and then increase progressively thereafter. 
This example illustrates how the potential for a hydromechanical coupling response may be simply conceptualised for any mine slope. The reduction in stress due to mining is principally in two directions; vertically and horizontally normal to the mine slope. Given this, then the question becomes what is the orientation of the defects compared to these two orientations? The question should be evaluated first for the defects of the highest geological order and or those that are the most continuous. The evaluation then progress to consideration of all the defect groups. In many mine slope situations, the critical orientations, are sub-vertical, dipping into the slope (toppling mode), subparallel to the slope and sometimes sub-horizontal.

Based on the concepts, testing and ideas described in Sections 2 and 3, it is possible to describe the stages of a typical hydromechanical coupling process for a mine slope in a generic rock mass:

1. During excavation of the mine slope, the in situ stresses change progressively.

2. This causes a range of responses within the rock mass more widely and specifically within individual defects. The range of responses is the result of the interactions between the in situ stress, rock mass modulus, rock mass geotechnical character, defect orientations and patterns; and defect character, and mine slope geometry.

3. The principal impact of these responses are changes in aperture, increasing both the hydraulic conductivity and storage of defects in the rock mass.

4. The early effects are on the long or first order defects.

5. Initially, this can result in decreases in the water levels and or water pressures in these major defects; and sometimes generally in the rock mass.

6. If the movements are only elastic, then the hydromechanical coupling process may stop.

7. However, if movements continue, changes also occur progressively to the apertures and hence hydraulic conductivities and storages of the other defects.

8. The magnitude of the changes is a function of both the type of defect, the type of movement on the defect, the scale of the movements and the orientation of the defects relative to the slope. This effect is best conceptualised using simple kinematic movement concepts focussing on the main defect sets and the major defects.

9. In a very dry climate, these impacts will generally all be positive in reducing groundwater levels or pressures.

10.However, in wetter climates or climates with a pronounced wet and dry season, these changes will result in modifications to the groundwater and groundwater responses over time due to transient rainfall recharge loading events.

11.The loading events cause movements and the movements cause increased aperture, modifying the groundwater responses progressively over time. This is an interactive process.

12. The modifications tend to follow a consistent pattern, manifested early in the cycle as general rises in levels or pressures, but changing gradually over time and as movement progresses to higher, more immediate, shorter duration, peak responses that are short-lived. This pattern is associated with general breakup of the rock mass and interconnection of defects.

13.In first order defects, the responses to rainfall runoff are generally quite 'peaky' with both rapid rises and falls.

14.In altered or brecciated or fine-grained or low strength masses, the responses to rainfall runoff are usually manifested as general rises in pore pressures, which may or may not be permanent.

15.The interaction between the climate and the geotechnical setting then governs the longer-term overall behaviour of the mine slope. 


\section{$5 \quad$ Lochiel trial pit}

\subsection{Description}

The Lochiel Trial Pit was excavated in a deposit of soft brown coal (lignite) $130 \mathrm{~km}$ north of Adelaide, Australia. The trial pit, completed in 1987, was part of studies to develop mine and power station designs to estimate the cost of electricity generation. Although only a trial, the pit depth was at full mine scale ( $\mathrm{O}^{\prime}$ Brien \& Sullivan 1988).

The geological profile consisted of three coal seams under 20 to $60 \mathrm{~m}$ of overburden. The area partially underlies a large salt lake. The overburden comprises thick fine-grained soil strength material with multiple sand aquifers and up to $20 \mathrm{~m}$ of artesian groundwater pressure (Figure 9).

This combination of site factors resulted in difficult mining conditions. Unless the sequence could be satisfactorily depressurised, draglines would be excluded because of very poor stability conditions for highwalls, pit floor and spoil piles.

The project milestones were recorded in days from the start of the dewatering, day zero. The other key milestone days were:

1. Day 140: the start of the pre-strip excavation.

2. Day 173: pre-strip completed.

3. Day 239: collapse of the trial slope.

\begin{tabular}{|c|c|c|c|c|c|}
\hline & UNIT & & MATERIAL & STRUCTURE & HYDROGEOLOGY \\
\hline \multirow{3}{*}{ 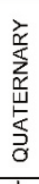 } & GYPSUM HILL & & CLAY, CH & & $\begin{array}{l}\text { PERCHED SURFACE } \\
\text { AQUIFER }\end{array}$ \\
\hline & HINDMARSH EQUIVALENT & & CLAY, CH & FISSURED & \\
\hline & NYOWEE BEDS & $1 / 1 /$ & CLAY, CL & & \\
\hline \multirow{7}{*}{ 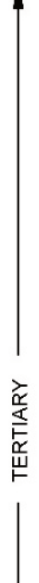 } & TARELLA SILT & & SILT, ML & $\begin{array}{c}\text { JOINTED } \\
\text { _ SHEAR } \\
\text { ZONE } \\
\end{array}$ & \\
\hline & WARRINDI SILT & & $\begin{array}{l}\text { SAND, } \\
\text { SILTY SAND }\end{array}$ & & AQUIFER \\
\hline & F\& F/G SEAMS & $\therefore \therefore: \because: \because 0^{\circ}$ & & & \\
\hline & G SEAMS & & LIGNITE & $\begin{array}{l}\text { SAND } \\
\text { FILLED } \\
\text { JOINTS }\end{array}$ & $\begin{array}{c}\text { PARTIAL } \\
\text { AQUICLUDE }\end{array}$ \\
\hline & G/H PARTING & $\because \because \because \because \because \because \because \because \div \div$ & SILTY SAND & & \\
\hline & H SEAMS & & LIGNITE & & \\
\hline & CONDOWIE SILT & & $\begin{array}{l}\text { SAND } \\
\text { SILT }\end{array}$ & & AQUIFER \\
\hline
\end{tabular}

Figure 9 Lochiel stratigraphic column and geotechnical units

Many units contained significant geological structures. The structure in each unit is shown schematically in the stratigraphic column (Figure 9). In summary, the key features which played significant roles in the movements and hydromechanical coupling were:

1. Gypsum Hill: a hard to slightly cemented clay with some leached zones and locally towards the base a minor shallow aquifer.

2. Hindmarsh clay: heavily overconsolidated, hard, fissured clay. 
3. Tarella silt: a stiff to very stiff clayey silt, with a prominent set of sub-vertical, continuous, open joints (Figure 10). The joints formed one prominent set aligned northwest to southeast.

4. Tarella silt (lower): a bedding plane shear zone, continuous over kilometres through the deposit.

5. Coal seams: sand-filled joints.

\subsection{Relevance to hydromechanical coupling}

This case study is directly relevant to the topics addressed in this paper because:

1. The pit was preceded by extensive geological, groundwater and geotechnical investigations.

2. Because the materials are of soil strength, the movement magnitudes are relatively large and thus more readily captured and understood.

3. Although the materials are of soil strength, some units contained geological structures so there was both continuum to discontinuum mechanics operating.

4. One slope was over-steepened so that it would fail when the excavation reached final depth. Hence all the stages from initial excavation to collapse were monitored (trial slope).

5. There were a total of 340 instruments measured daily to weekly.

6. The instruments were installed to measure the movement of groundwater with time and excavation, the response of the ground itself to dewatering, depressurisation and excavation; surface and subsurface movements, and changes in in situ stress.

7. The pit was also designed to evaluate the effects of unloading on porewater pressures in the fine-grained soils.
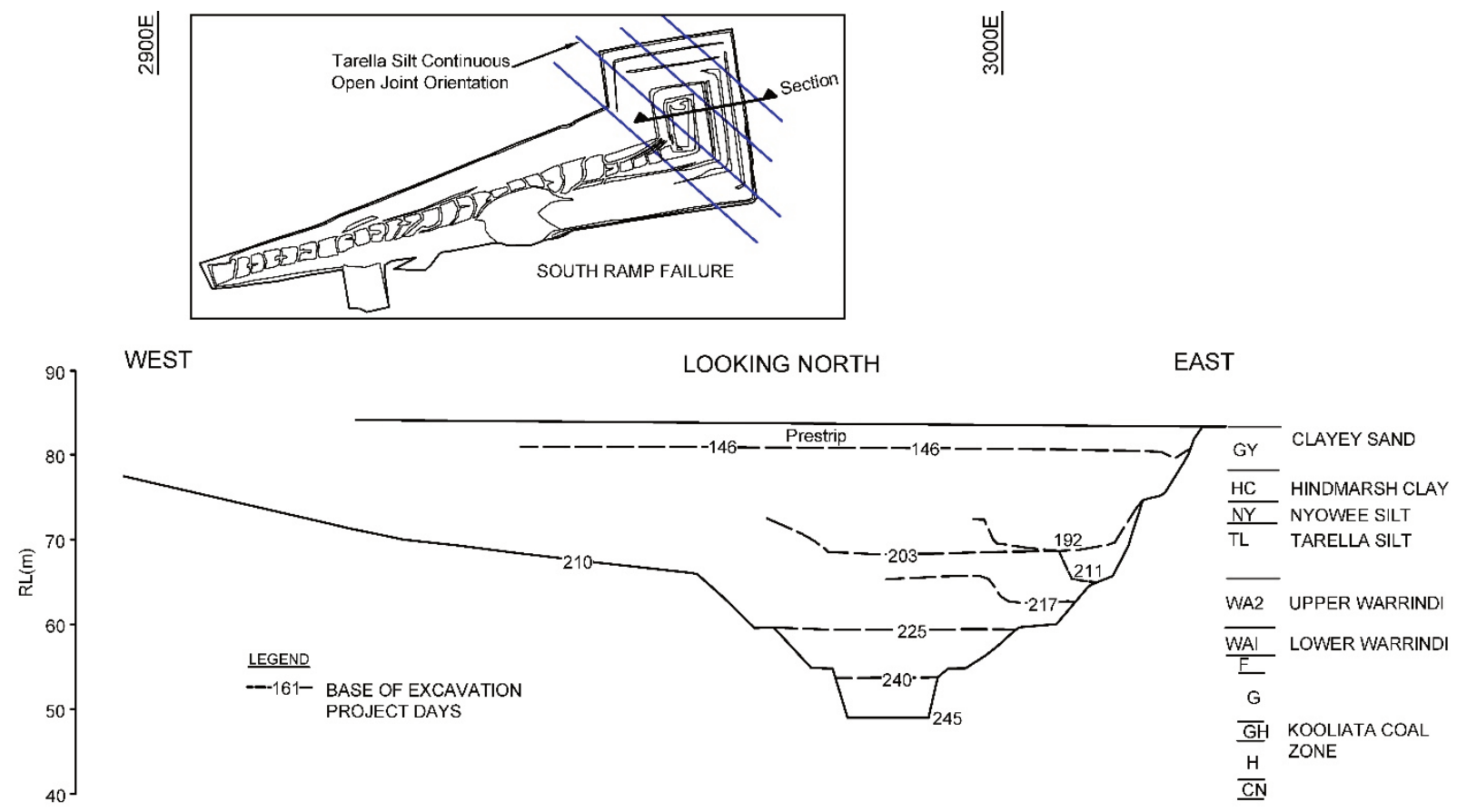

Figure 10 Plan and section through the trial pit showing the orientation of open joints in Tarella silt and trial slope (east wall)

\subsection{Dimensions and pit sequencing}

The pit was designed as a $100 \mathrm{~m}$ square excavation with a straight ramp about $300 \mathrm{~m}$ long providing access to the bottom (Figure 10). The slope of the walls was about $42.5^{\circ}$, except for the east wall trial slope. The trial slope angle was excavated at 60 to $75^{\circ}$ and designed to collapse after excavation was completed. The project 
comprised several phases, including a $9 \mathrm{~m}$ deep pre-strip followed by excavation to the base of the coal seams.

\subsection{Dewatering and depressurisation}

The sequence contained several thin aquifers separating beds of fine-grained clay, silt and lignite. These beds were fully saturated. Although conventional wisdom suggests that the drainage of clay and silt strata cannot be achieved within practicable time scales due to the inherent low hydraulic conductivity, a series of field trials had demonstrated depressurisation was achievable (Sullivan \& Burman 1986).

The trial pit instrumentation measured the pore pressure decreases due to both unloading, equivalent to the pre-strip in dragline mining, and to the main excavation. Depressurisation due to unloading, which is an important hydromechanical coupling effect, certainly occurs and can be measured. However, the amount of depressurisation is not directly related to the total overburden stress reduction but to the change in the bulk stress at any point in the slope. Depending on the excavation shape, history and nature of materials, the pre-existing horizontal stresses can be transferred to the base of the excavation and this can result in smaller pore pressure reductions than indicated by vertical unloading.

\subsection{Ground movements and trial slope}

Because the trial slope was designed to be on the point of failure, many minor failures occurred progressively throughout the excavation phase. Hence it was a qualified success, not exactly replicating the pre-excavation limit equilibrium analyses.

Figure 11(a) shows the main movement stages, from initial dewatering up to the final collapse. Because of the intensive monitoring and the rigorous monitoring program, it was possible to piece together the progression of movements leading up to failure. The movements were very complex and linked to the physical processes, the geological structure, in situ stress and then leading into pre-failure and collapse related movements.

The main stages and the related movements were:

1. Settlement (Days 0 to 140): start of excavation, with 70 to $80 \mathrm{~mm}$ of ground settlement due to dewatering and depressurisation.

2. Rebound (Day 173): excavation through the overconsolidated upper units. Rebound of ground surface outside the pit crest $(8 \mathrm{~mm})$ and $2 \mathrm{~mm}$ shear displacement on Tarella shear zone, even though it was not yet daylighted.

3. Relaxation and shear (Day 188): excavation into the top of Tarella silt. Relaxation and downward movement of ground outside the pit crest and $5 \mathrm{~mm}$ shear displacement on Tarella shear zone, still not daylighted.

4. Face failure, shear and rebound (Day 207): the Tarella shear zone is daylighted with $18 \mathrm{~mm}$ of shear displacement, local sloughing failure of the face of the upper overconsolidated units and rebound outside the pit crest.

5. Global slope movements and shear movements stop (Day 217): excavation to the base of the Tarella silt unit. General rotational type slope movements down and into the pit and upwards and outwards at the slope face. This is accompanied by an addition $9 \mathrm{~mm}$ displacement on the Tarella shear zone, which then stopped moving.

6. Pre-failure movements (Day 227): general rotational slope movements of whole east wall.

7. Collapse, shear, tension cracking and rebound (Day 239): ongoing excavation to the coal zone. Collapse movements into the pit, re-initiation of shear on the Tarella shear zone, which shears-off the inclinometer, development of a tension crack well behind the crest and rebound of the ground surface outside the tension crack. 
Figure $11(b)$ is a plan view showing the horizontal movement vectors over time, with the day markers approximate the periods in Figure 11(a). Also shown for emphasis is the approximate mean movement direction for each period, which shows:

1. Excavation through the upper overconsolidated units results in movement towards the south-southwest.

2. As the upper Tarella silt is excavated, the vector of movement turns to the west, approximately normal to the trial slope.

3. After the Tarella shear zone is daylighted, the vectors turn towards the northwest subparallel to the principal joint direction (Figure 10).

4. The face prisms were all lost after Day 227, the pre-failure stage.

The interpretation of this pattern is that there are different stress orientations in the upper overconsolidated clays compared to the Tarella silt. In the Tarella silt, the continuous joints all had significant apertures (measured in $\mathrm{mm}$ 's) and hence, the principal horizontal stress direction was inferred to be oriented parallel to these joints, resulting in the observed movement directions.

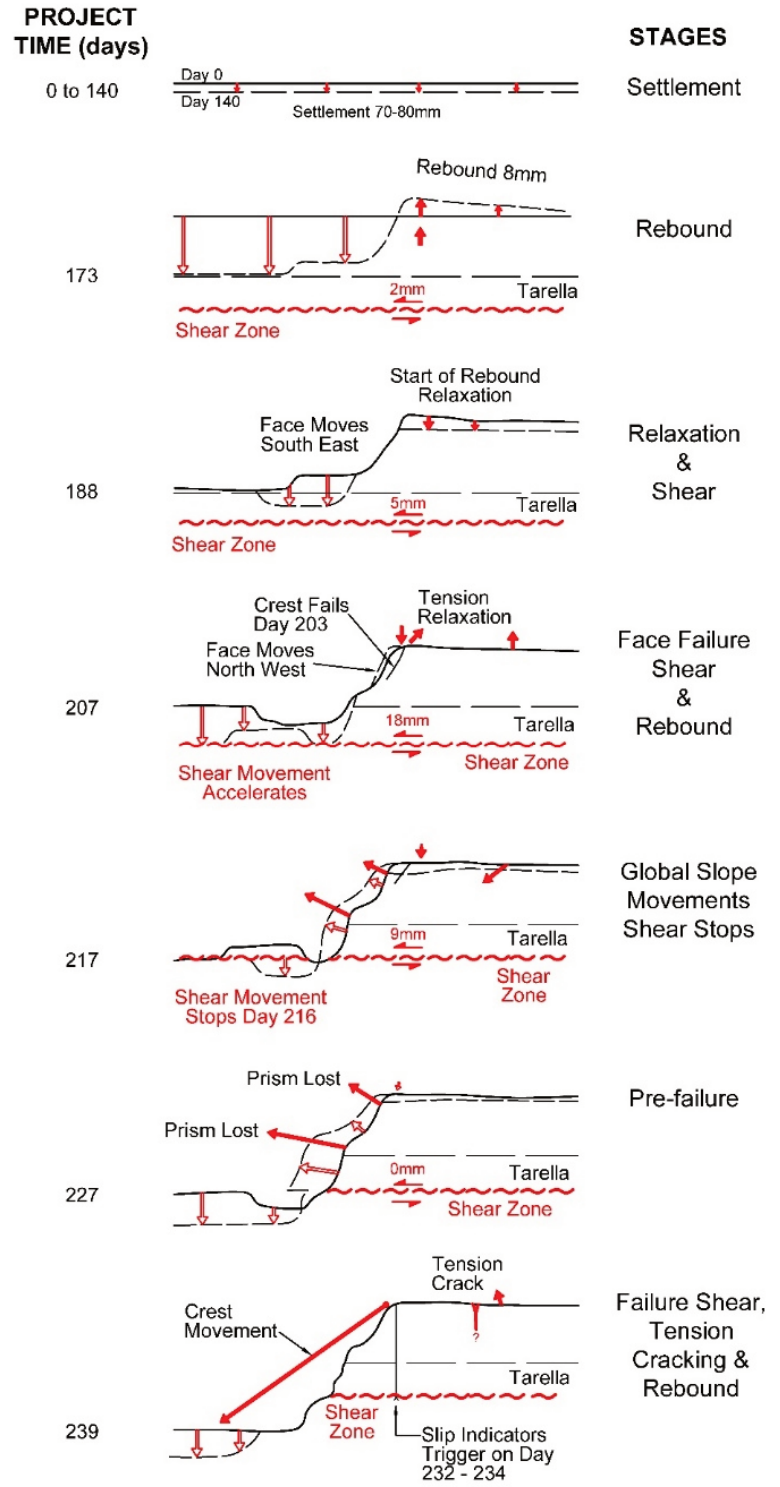

(a)

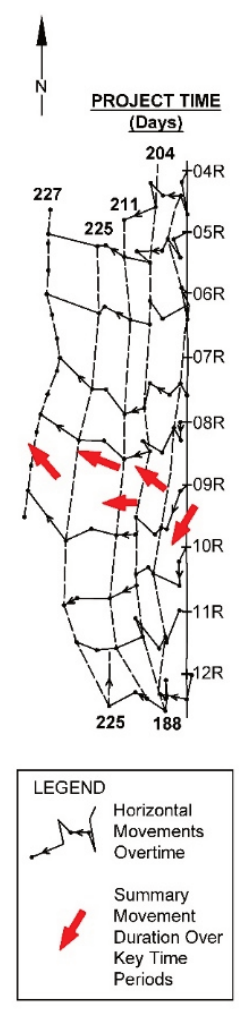

(b)

Figure 11 Summary of ground movements for the trial slope in section (a) and plan (b) 


\subsection{The hydromechanical coupling responses}

The movements were accompanied by a range of pore pressure responses, shown in section normal to the trial slope and as pore pressure profiles (Figures 12 and 13).

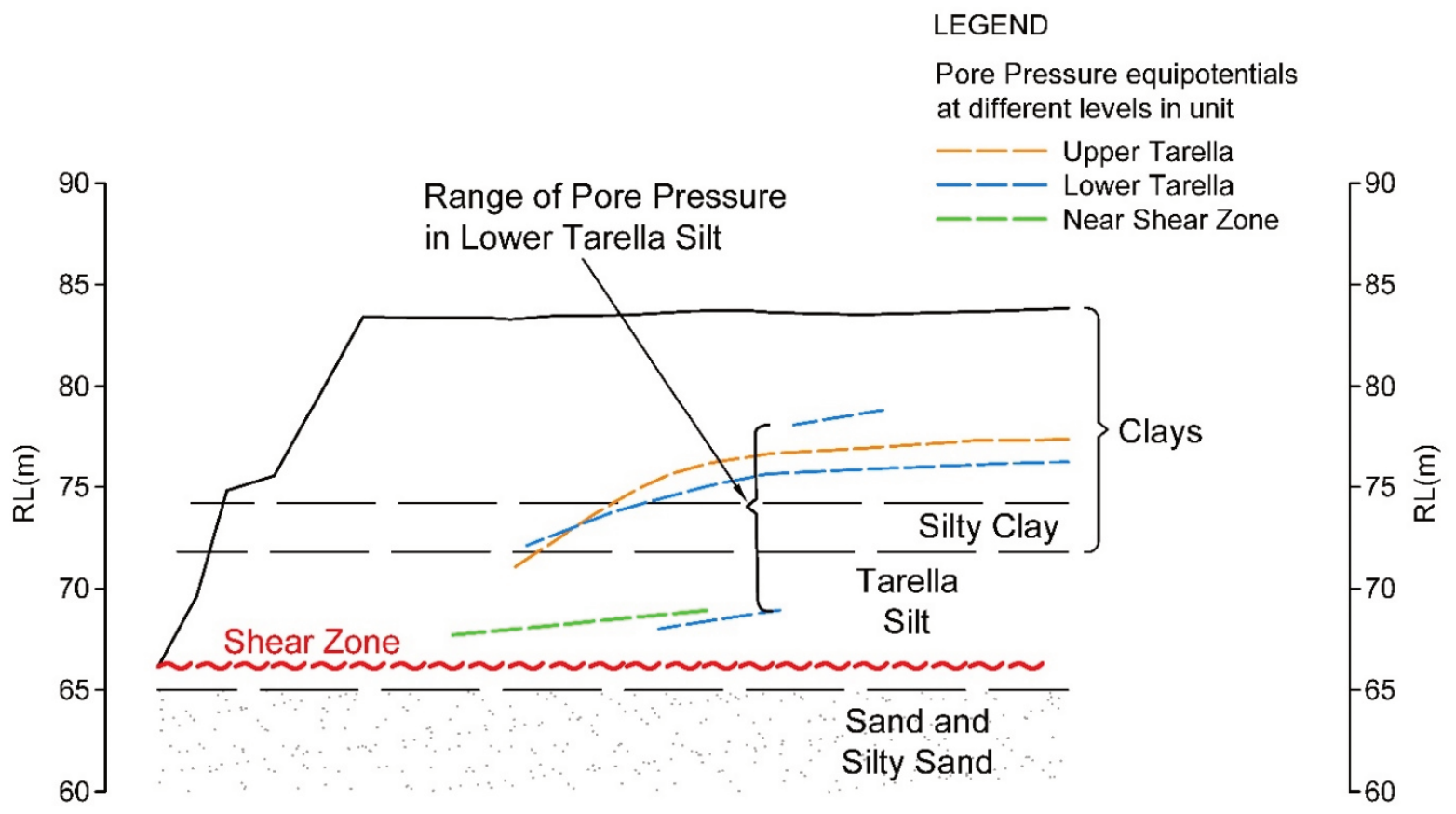

Figure 12 Section through the trial slope showing groundwater pressures in units

In Figure 13, the trial slope pore pressures are compared with the pressures in a stable location more remote from the trial pit. The measurements are for project Days 0 (start of project) and 240 (immediately after collapse of east wall).

The principal responses and behaviours of note are:

1. Although the remote location is not near the trial pit, the depressurisation overall in the upper overconsolidated clays and Tarella silt is greater and more uniform overall.

2. Immediately behind the trial slope, the depressurisation is considerably less overall.

3. The responses in the jointed unit (Tarella silt) above the shear zone are very variable.

4. The depressurisation behind the slope failure in the jointed Tarella silt above the shear zone are less than at the remote location.

These effects are all caused by hydromechanical coupling. They are a function of the complex movement patterns associated with relief of in situ horizontal stress, geological structure, and the geotechnical properties of the soil units and defects and failure related movements. The main hydromechanical coupling processes are:

1. The shear movements along the Tarella shear zone causes it to act as a hydrogeological barrier, perching pore pressures above it.

2. The open joints in the Tarella silt are aligned at an acute angle to the face. In plan view as the unit displaces due to stress relief and then pre-failure movements, the joints undergo complex opening and shear movements. This causes the defects to show both opening, which allows drainage and blocking, which inhibits drainage.

3. At the same time, interaction between the movement on the bedding plane shear and opening/closing of the sub-vertical joints in the Tarella silt results in complex aperture development, also both enhancing and inhibiting depressurisation. 


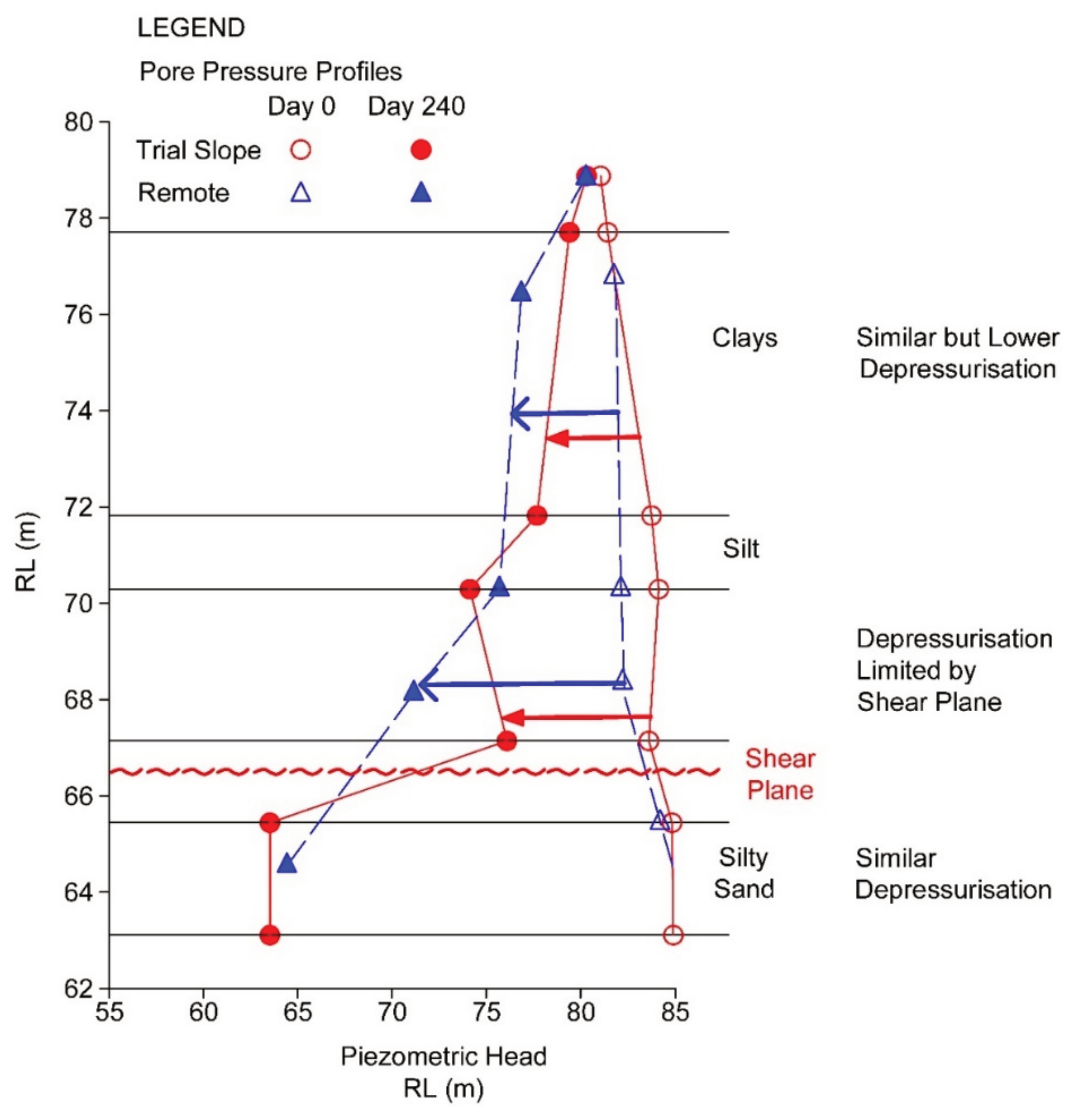

Figure 13 Pore pressure profiles at the start of the project and immediately after collapse

\subsection{Important hydromechanical coupling lessons}

This case study highlights some very important overall lessons for hydromechanical coupling responses: firstly with respect to higher order geological defects and secondly, with respect to the masses either overlying or underlying any such structure:

1. If there is a low strength, higher order, geological structure located behind a slope in an orientation favourable for movement, then shear deformations will occur and it will in generally act as a hydrogeological barrier.

2. Consequently, depending on the climate, rainfall runoff events will result in transient groundwater responses in a soil/rock mass that are perched above the structure.

3. Obtaining a reliable overall measure of the groundwater pressures or levels in the soil/rock mass above the higher order structure is difficult because the responses are nearly always very variable.

4. The groundwater responses above the higher order structure will be highly variable, both positive and negative, may show sharp rises or falls, or alternatively more steady overall rises or falls.

5. Hence, when a hydromechanical coupling response occurs above a defect undergoing shear deformations it is not the magnitude of a response that is important. The most important consideration is the fact there is a response.

6. In certain geotechnical settings, the movement along the higher order geological defect can isolate the mass below the defect from any near surface transient groundwater effects.

This pattern of behaviour was also replicated by groundwater monitoring collated as part of the Yallourn Mine Batter Failure Inquiry (Sullivan 2008). In that example, a $6 \mathrm{Mm}^{3}$ mine slope failure formed a direct hydraulic connection with the Yallourn River during pre-failure movements. Despite access to a limitless supply of water and the presence of continuous, sub-vertical joints intersecting the river, highly variable 
groundwater responses occurred. The observed patterns were similar to those described in Points 3 and 4 in the list at the beginning of Section 5.7. Importantly, there was no consistent overall rise to a single elevation through the mass, which would have been expected given that continuous joints daylighted in a river. This is one of the key lessons and is fundamentally important to understanding and management of mine slopes.

\section{$6 \quad$ Layered footwalls}

\subsection{Introduction}

Most conventional mining developments in low to moderately dipping layered deposits consist of:

- Mining in a series of strike advance panels.

- Mining down-dip within each panel in a series of benches.

This has two impacts. Firstly, the stresses are changing within each panel throughout the panel life and secondly, comprehensive holistic monitoring data is often limited. These two factors in combination make comprehensive interpretation difficult. Notwithstanding this, some detailed information on one or more technical element is often available from each of the different sites. Combining these different elements from the different mine sites has allowed integration into a more complete understanding of layered footwalls and their responses to mining and the environment.

In simple terms, the mechanics of the hydromechanical coupling in layered footwalls is dominated by four main factors:

1. The dip angle of the bedding and or layering $(\alpha)$.

2. The presence of low strength shears or clay seams parallel to the bedding and/or layering.

3. The number of and depth of these low strength planes below the footwall.

4. The intact rock strength as determined by a uniaxial compressive strength (UCS) test.

\subsection{Typical footwall movement patterns}

Figure 14 shows the prism displacement plot for a footwall that started moving in 2011 and failed in September 2015. The footwall showed long-term very low level creep movements, with approximately $200 \mathrm{~mm}$ of displacement over four years. This was followed by increased movements over a five to six month period, before an apparent stabilisation. This was followed by sudden failure in September 2015. Close inspection of Figure 14 shows that the long-term creep comprises a series of cycles of increased movement followed by apparent stable periods. This pattern has now been observed at many different mine sites in different rock materials and of different strength. At this location borehole inclinometers confirmed movement of a $10 \mathrm{~m}$ thick footwall slab.

Figure 15 summarises the typical movement patterns that are observed, Types A, B and C:

1. Stage 1: long-term creep of the footwall slab, sometimes extending for up to six years.

2. Stage 2: is interpreted to represent the development of residual strength across the majority of the footwall slab, which is then able to move bodily as a mass, loading the toe.

3. Stage 3: apparent stabilisation, but interpreted to represent transfer of the loading from the footwall slab onto the rock mass in the toe region. This ignores some loading, which is also transferred onto the sides of the footwall slab.

4. Stage 4: yielding of the rock mass in the toe region, leading to pre-failure and collapse movements.

In Figure 15, Types A and B are essentially the same with the exception that Type B has several smaller cycles in the creep phase (Stage 1). Type $C$ is a pattern often observed in very strong rock masses where there are only 
very small movements which appear to stabilise (Stage 3) without development of a Stage 2. Type C rock masses often show very sudden failure. Each mine site is unique in terms of movement rates and total movements in each stage. However, experience from across a wide spectrum of materials gives some general guidance:

1. Stage 1:

a. Very strong rock mass: $0.02 \mathrm{~mm} /$ day.

b. Lower strength rock mass: 0.06 to $0.14 \mathrm{~mm} /$ day.

2. Stage 2:

a. Very strong rock mass: 0.02 to $0.15 \mathrm{~mm} /$ day.

b. Lower strength rock mass: 0.3 to $1.4 \mathrm{~mm} /$ day.

3. In Stage 4, the collapse movement time can be as little as 45 minutes and the potential for sudden brittle failure should be allowed for in management of the slope.

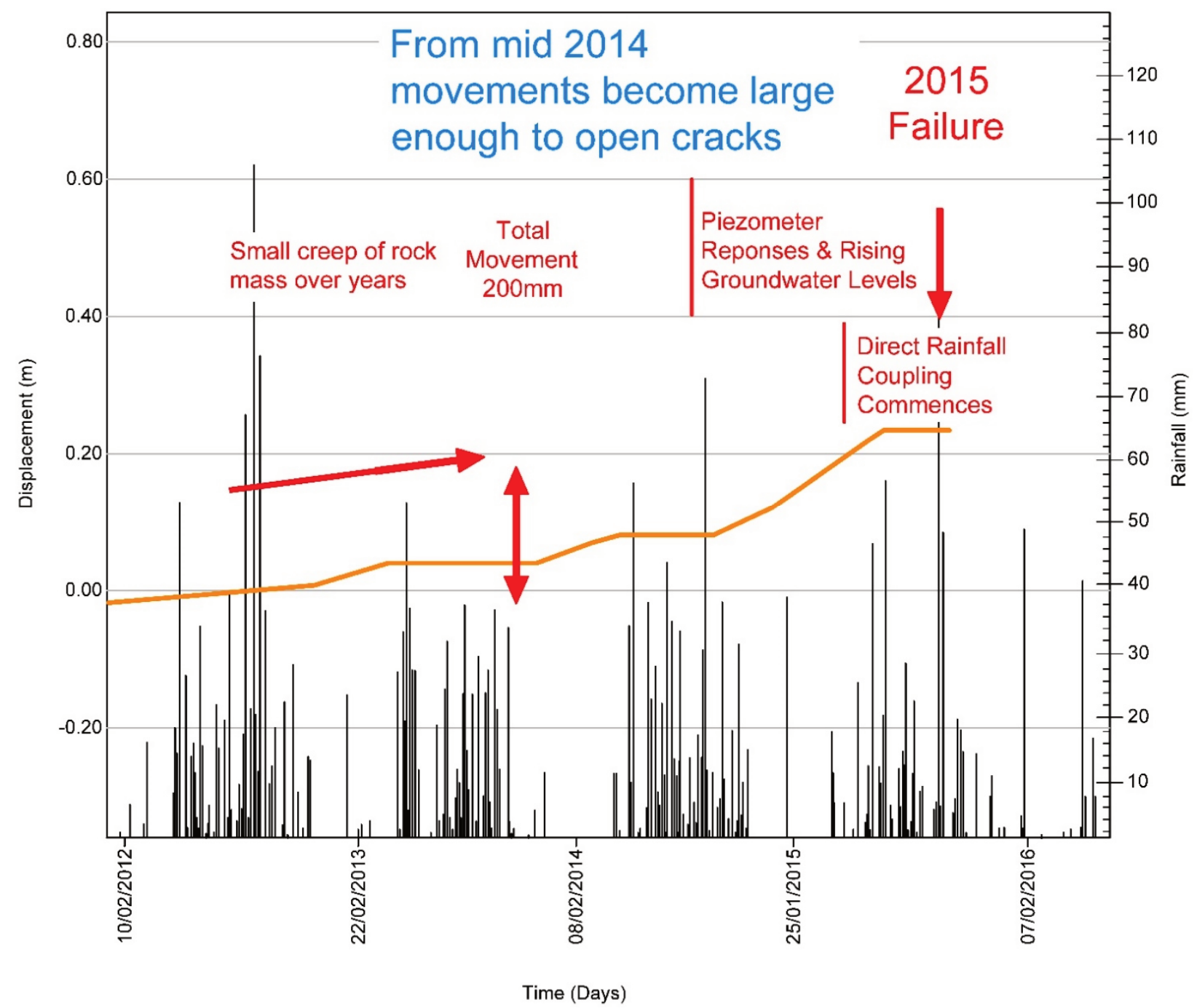

Figure 14 Typical footwall movement pattern, long-term creep movement in a series of cycles, an increased movement rate, followed by an apparent stabilisation, just prior to failure. These movement stages are linked to groundwater responses as shown

The key lesson is that the monitoring data should not be viewed within the traditional concepts used for understanding time versus displacement prism graphs. Slowing and stopping of the movements (Stage 3) is not stabilisation. This is a precursor stage to collapse and represents the change to a different mechanism 
controlling the stability of the mass. In Stages 1 and 2, the defect plane at the base of the footwall slab is progressively reducing to residual strength, which occurs sometime in Stage 2.

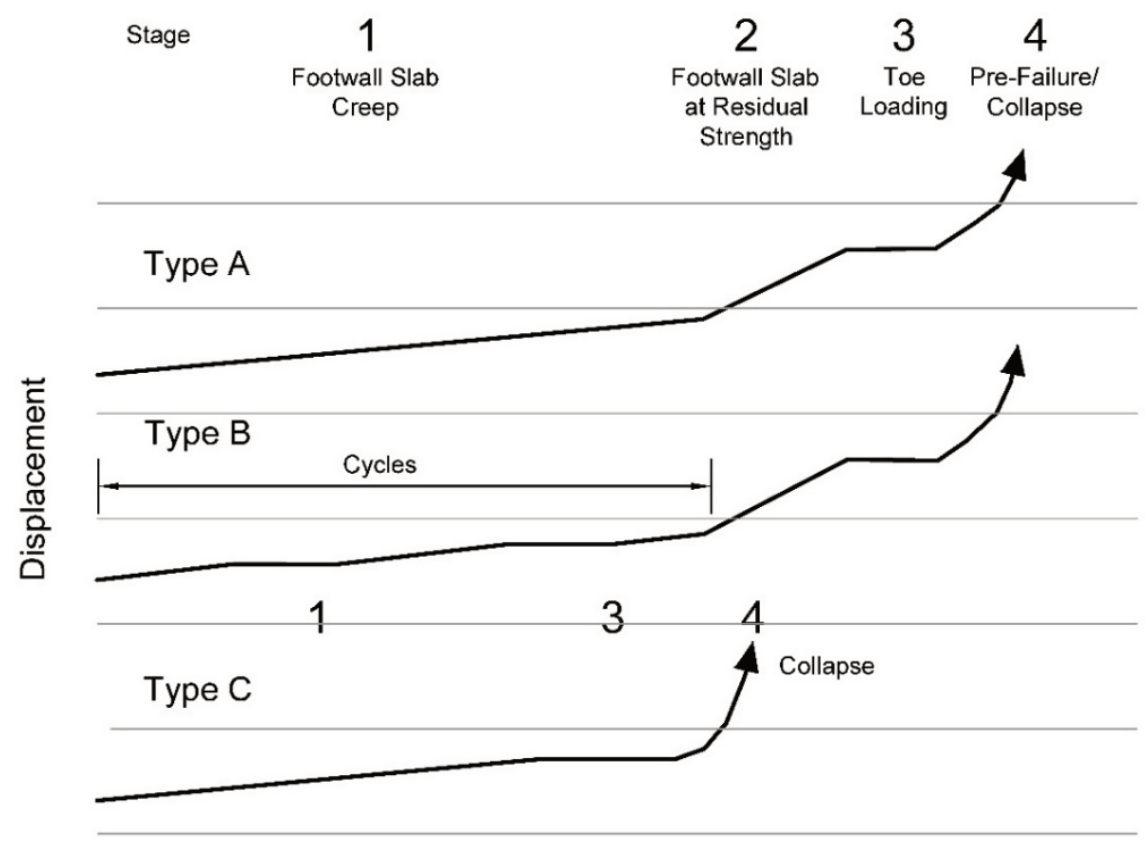

Time

Figure 15 Typical footwall movement type patterns and stages, with the interpretation of the meaning of each stage

\subsection{Progressive failure}

\subsubsection{Geotechnical setting}

The footwall of the Collie coal mine, Western Australia, was heavily cable bolted (Sullivan 1994). The footwall movements were intensively monitored for more than four years before failure occurred 45 minutes after the alarms were triggered. The rocks were of low to medium intact strength (UCS of 10 to $15 \mathrm{MPa}$ ) and, although folded up to $40^{\circ}$, were massive, relatively unjointed and without any discernible shearing parallel to bedding or clay seams. The overburden and sub-floor rocks were fully dewatered by a large-scale borehole pumping system and it appears groundwater did not play a significant part in this failure. However, the failure did occur during the wet season and some rainfall runoff probably did play a small role in the failure.

The extensive network of surface prisms, borehole extensometers and surface crack extensometers allowed the pattern of surface and subsurface movements over time to be evaluated. At the time it was thought the movement pattern was caused in part by the presence of the cable bolting (Sullivan 1994). However, it is now clear by comparison with many other footwall slopes that the movements all follow similar patterns and stages, largely irrespective of the intact strength (Figure 15).

\subsubsection{Development of progressive failure}

Notwithstanding the presence of the cable bolting, this footwall followed the typical footwall movement pattern described in Section 6.2. However, the most important lesson arising from this case study is the time dependent development of the footwall deformations in the two years prior to failure which entailed (Figure 16):

1. January 1989 , tension cracks developed along crest.

2. June 1992, Stage 2 movements occurred over an area approximating $25 \%$ of the failure area. 
3. July 1992, Stage 2 movements spread to an adjacent area south, increasing to around $40 \%$ of the failure area.

4. September 1992 to March 1993, the movement extended at depth behind this area as recorded by extensometers.

5. September to November 1992, movements spread up slope and to the south, now covering around $75 \%$ of the area.

6. April to May 1993, movements spread upslope to the west.

7. June 1994, failure.

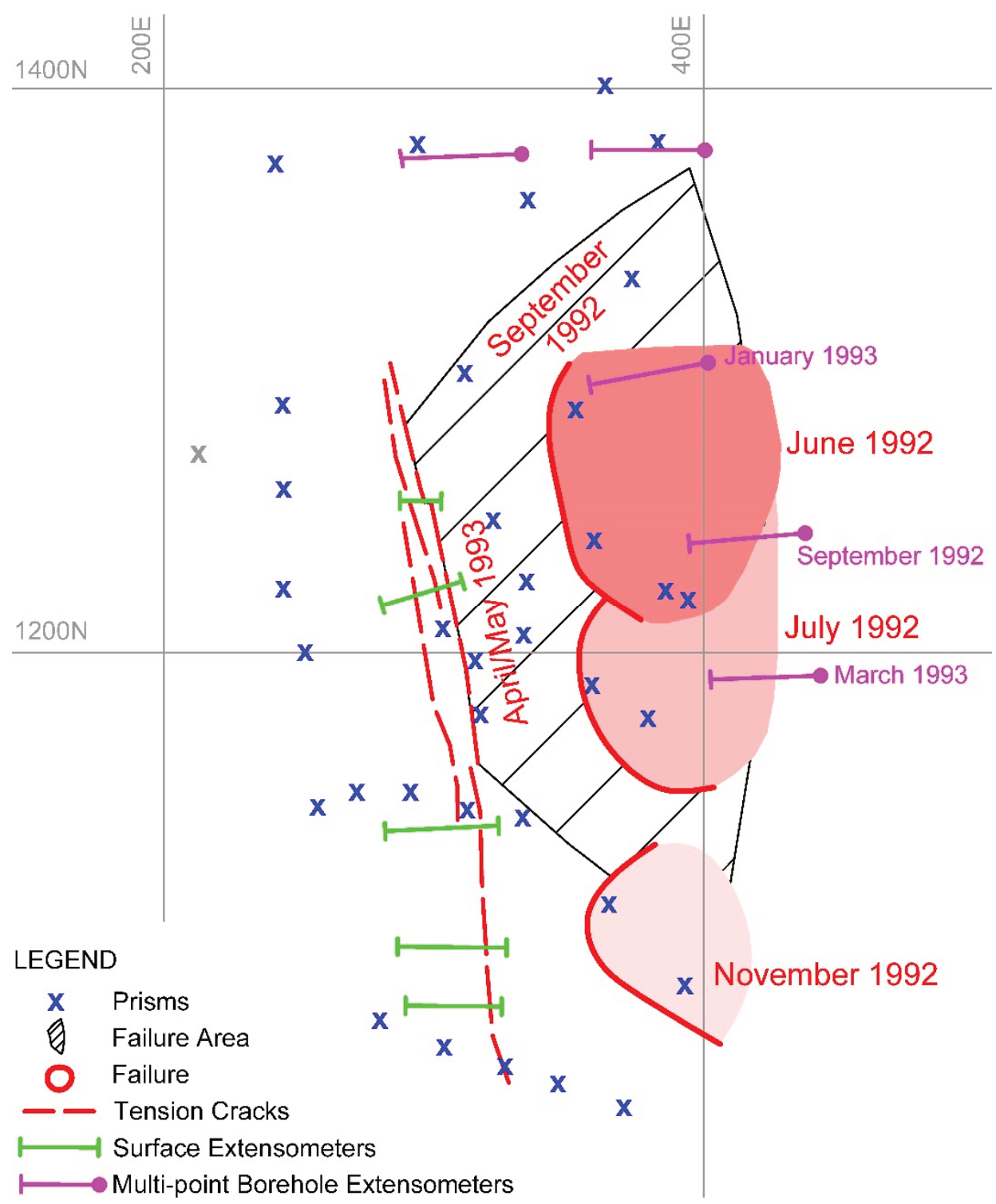

Figure 16 Collie coal mine footwall showing the progressive time dependent development of movements in the footwall slab leading up to eventual failure of the slope

This example clearly demonstrates the progressive development of failure through the footwall slab over a period of two years prior to collapse. Different segments of the footwall progressively passed from Stages 1 to 2 . The initial area comprised $25 \%$ of the final collapse area and once movements increased in this area, the load was transferred to adjacent areas, progressively spreading to encompass the whole area, which then entered Stage 3. 
In this case study, Stage 2 movements were initiated in the central lower region of the slope. However, in other geotechnical settings, Stage 2 develops firstly in the upper portions of the slope.

\subsection{Hydromechanical coupling responses}

Figure 17 shows the piezometer hydrographs for the slope covered by the prism data in Figure 14. This hydrograph illustrates the pore pressure responses in Stages 1 to 4 (Figure 15). The shallow piezometers in the unstable slab start rising over a year before the collapse of the slope. The rise starts about halfway through the rain season. Movements continue, allowing development of peak responses to higher rainfall events as the defect apertures increase. The deeper piezometers also start rising but this occurs around nine months after the shallow piezometers. There are no peak responses in the deeper responses because the shear displacement along the sub-floor clay seam has formed a hydraulic barrier.

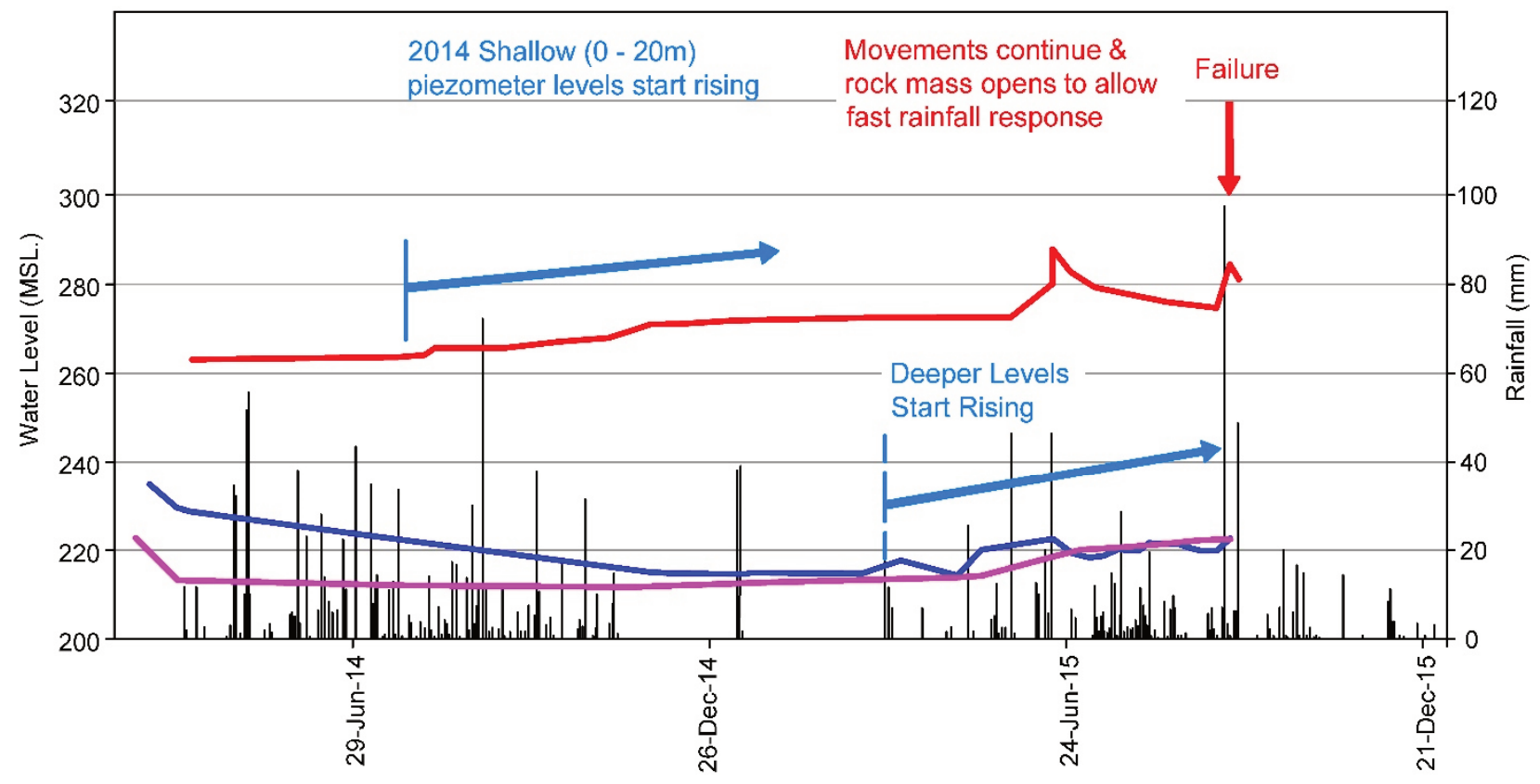

Groundwater Pressures

$\longrightarrow$ Deeper

Figure 17 Hydrograph showing the footwall pore pressures over time leading up to failure. The piezometers are located at two levels, above and below the footwall clay seam where shearing is occurring. The hydrograph starts near the end of Stage 1 (Figure 15) and shows the groundwater responses for Stages 2 to 4

Figure 18 shows the footwall groundwater responses for another mine in the period leading up to cracking and widespread movement. The piezometers are located on a section in the lower third of the slope (piezometer 1) and near the toe (piezometer 2). There are multi-level piezometers at each location, with the shallow piezometers above the sub-floor clay seam. In piezometer 1 , the shallow piezometers start showing a hydromechanical coupling response approximately two months before failure and this is accompanied by a general rise in deeper groundwater pressures. In piezometer 2, the shallow piezometer shows minimal rainfall impacts and all the groundwater pressure changes occur in the deeper piezometers. This site has a network of vertical pressure relief drains $40 \mathrm{~m}$ deep across the footwall and these drains have probably affected some of the deeper groundwater responses. 

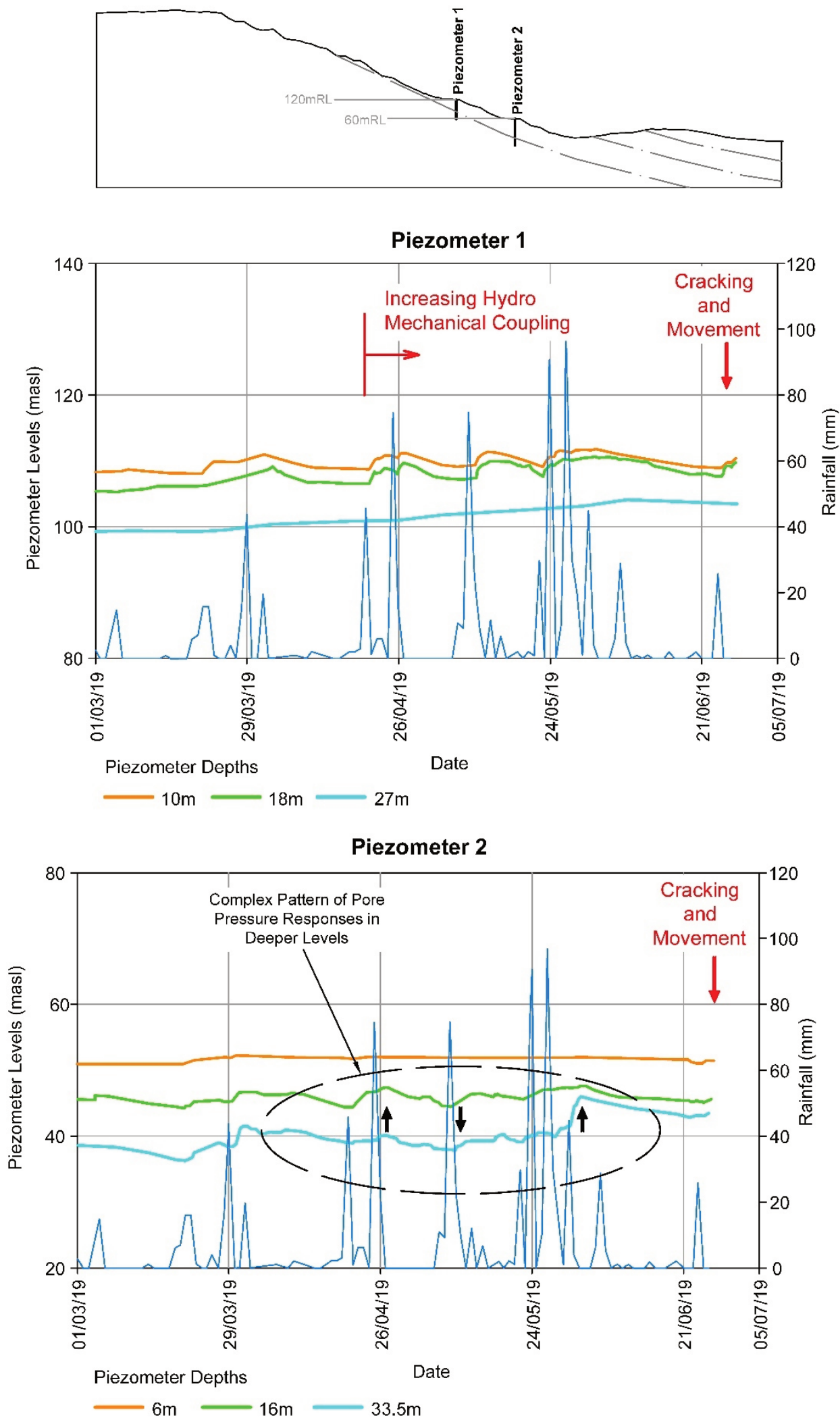

Figure 18 Example of pore pressure responses of a footwall in period leading up to cracking and widespread movement. This is equivalent to the final part of Stages 2, 3 and 4. The data is for shallow and deeper piezometers, above and below the sub-floor shear plane. The piezometers are at two elevations in the footwall 


\subsection{Footwall geotechnical models}

Experience has shown that there are some common factors and elements of inclined bedded materials that affect performance at the mine slope scale (Sullivan \& Burman 1985):

1. In nearly all cases, there are lower strength planes subparallel to bedding or the layering.

2. These layers will invariable control and or strongly influence movements, groundwater responses, and responses to rainfall/runoff.

3. The behaviours can often be a function of the ratio between the intact UCS strength and the residual strength of any sub-floor bedding or layering defects.

4. Although initially stability may be controlled by the peak strength of the low strength bedding or layering defects, strength loss with time and creep is to be expected.

5. The design shear strength for bedding plane shears or clay seams should in almost all cases be the residual strength.

6. The lower strength planes result in the formation of new and different hydrogeological domains over time that tend to form subparallel to the slope. This may entail either a two or three layer system:

a. An upper layer where behaviour and responses are controlled or driven by the local environment (rainfall/runoff).

b. A deeper or intermediate layer.

c. Lower layer where groundwater pressures may remain relatively unchanged or may become largely depressurised.

7. There is generally a well-defined sequence of footwall movements:

a. Which starts with creep movements, which tend to occur in all cases except very high strength rock.

b. These elastic movements almost invariably lead to some small shear on bedding or layering because it is the long continuous low strength planes that control behaviour.

c. This also results in opening of other pre-existing defects.

d. In stronger materials, the extent of these deformations will in general be of more limited depth.

e. However, in weaker materials the effects may continue to extend over time, both laterally away from the crest and or at depth behind the slope.

f. Creep movements continue and or increase with increasing shear along bedding and/or layering.

g. These movements become concentrated in the shallower layers, but may also be multistoryed.

h. Pre-existing defects in the upper layers develop observable aperture (Figure 19).

i. New tension cracks may form near the pit crest and in lower strength material.

j. Failure occurs.

8. All these movements are very closely linked with specific groundwater and rainfall runoff responses, the hydromechanical coupling:

a. Initially, there is often little, if any, response in piezometers and limited fluctuations with rainfall.

b. Then groundwater level falls occur particularly in shallow to intermediate piezometers.

c. Over time and with continued mining, shallow groundwater responses to rainfall runoff increase, with reducing time-lag to rainfall events. 
d. Pressures in intermediate to deeper piezometers may start increasing.

e. There is potential for hydraulic connections with water courses and water bodies outside pit crest and intermediate to deeper piezometers to show no response and or start rising.

f. A rainfall event causes failure of upper layer and lower layers show limited or no response.

9. In summary, the whole slope starts reacting to excavation and showing some responses that gradually increase in magnitude and with decreased time-lag. The responses progressively become concentrated in the shallower layers, while the deeper layers become progressively more isolated from near surface environmental impacts.

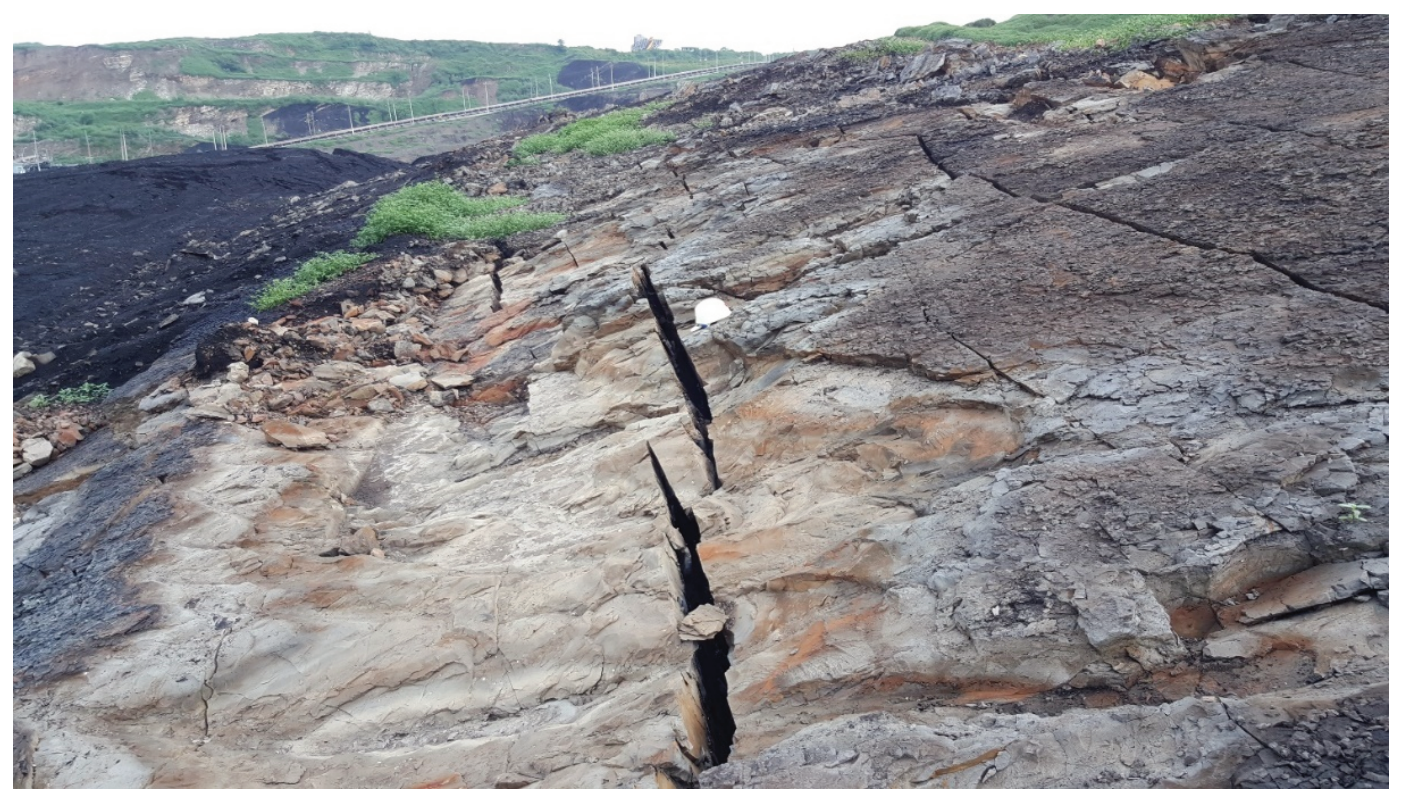

Figure 19 A typical footwall showing aperture development on joints in an advanced stage of movement

This is shown schematically in Figure 20 for three mining phases. In Mining Phase 1 , the mine depth is relatively shallow and the depth of the thickness of the sub-floor slab is large compared to the exposed footwall length. However, because the intact rock strength is very low to low, the mining still results in very small but measurable displacements of an upper footwall slab (Slab a) above a bedding plane shear. Displacements are small and there are minimal changes to groundwater in the footwall.

In Mining Phase 2, the exposed footwall length is now significant compared to the thickness of the sub-floor slab. Significant shear develops along the majority of the base of Slab a). There may also be minor shear developing at depth, Slab b). In this phase minor movements may also be recorded on the natural ground outside the footwall crest. Creep movements of the footwall would be occurring, movement Stage 1 in Figure 15. This will cause some depressurisation of the footwall, both shallow and deep.

In Mining Phase 3, a long footwall slab has been formed. Movement of the footwall slab will have continued and this now probably represents movement Stages 2 and 3 in Figure 15. Movements could also extend well outside the mine crest and where these movement zones intersect surface water bodies hydraulic connections will be formed, and groundwater levels will recover. Shallow groundwater in the footwall starts responding to rainfall runoff, but deeper groundwater levels continue to fall.

\subsection{Footwall creep ratio}

It is the author's experience that for many footwall slopes, considerations of Factor of Safety can be misleading because creep movements leading to progressive failure is the normal situation. Many footwall slopes with apparently a high or conventional design Factors of Safety as indicated by limit equilibrium stability analyses, subsequently fail. This does not occur early in the life of the slope but as excavation 
continues. This is because the simple limit equilibrium analysis fails to capture the time and stress dependent slope movements and the hydromechanical coupling processes.

This leads to a new concept for footwalls, termed the footwall creep ratio (FCR), which is the ratio of residual shear strength (angle of friction, $\varnothing$ ) of the low strength planes compared to the bedding dip angle $(\alpha)$, where the FCR $=\varnothing \div \alpha$. In an infinite slope, the FCR is equivalent to the Factor of Safety. The FCR is equivalent to an infinite slope analysis. However, it is conceptualised differently in this paper because both a limit equilibrium analysis and infinite slope analysis fail to capture the fundamental processes taking place over time in many of these slopes.

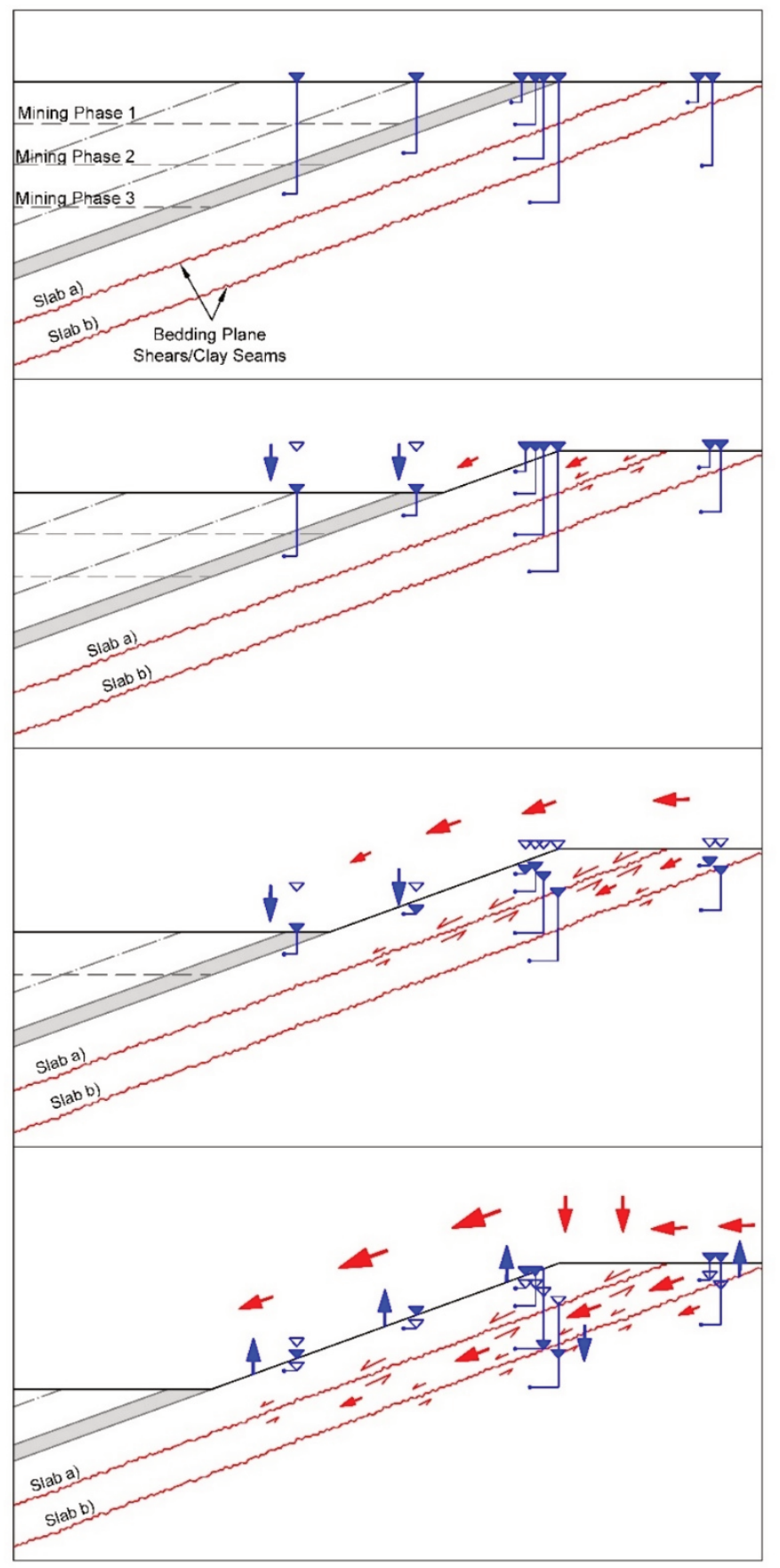

Pre-Mining

PHASE 1

1) Small creep of footwal commences

2) Footwall groundwater pressures unchanged

3) Pore pressures under mine floor reduce

\section{PHASE 2}

1) Shear displacement increase in Slab a)

2) Small shear displacement starts in Slab b)

3) Small horizontal movements well ouside crest

4) Pore pressure in Slab a) reduced

5) Deeper footwall piezometers show larger pore pressure reductions

\section{PHASE 3}

1) Shear displacement in Slab a) and Slab b)

2) Widespread movement horizontally and vertically outside mine area

3) Rebound of pore pressures after connection with surface water sources

4) Depressurisation at depth due to drainage and unloading

5) Pore pressure in Slab a) start responding to rainfall recharge events

Figure 20 Schematic model showing the development of surface and subsurface movements and the corresponding groundwater responses as a typical footwall is developed down-dip. Three phases of mining are shown 
The author has found the following general guidelines useful for predicting future performance:

1. $\mathbf{F C R}=1.1$ to 1.3: depending on the intact UCS, the depth of the low strength layers below the footwall and the environment, there is a low to medium chance that major instability will develop over time.

2. $\mathbf{F C R}=1.1$ to 0.9: creep movements will occur and chances of adverse hydromechanical coupling events will increase as the footwall length grows. There is a medium to high chance of failure in the future. Failure may occur years after initial creep movements commence.

3. FCR < 0.9: creep movements, adverse hydromechanical coupling events and failure will occur.

Generally, these guidelines have been found to be applicable for rocks with UCS from very low to medium strength. The concept may also apply in higher strength rocks, but this will depend on the particular site geotechnical setting and the environment.

\section{$7 \quad$ Analysis and management of footwall slope stability}

\subsection{Current practice analysis and management}

The stability of footwall slopes is usually analysed conventionally. Engineering models are developed, low strength planes are identified and tested, material parameters are determined, and the stability analyses carried out.

For most footwalls dipping at greater than about $5^{\circ}$ to $8^{\circ}$, the footwall will become marginally stable to unstable if the footwall becomes fully saturated, at least where the residual strength of the sub-floor seams is very low. In many mines, a sub-floor depressurisation and/or drainage system is installed, comprising either horizontal drains or vertical pressure relief drains. Some mines use piezometer footwall groundwater levels as triggers for allowing mining to continue. The slopes are monitored over time using prisms or radar or both.

However, it is the author's experience that in the many cases the future stability of a footwall slope bears little relationship to these calculations and analyses.

\subsection{Groundwater management of footwall slopes}

A key finding of this paper is that great care should be exercised when using groundwater level triggers for managing the stability of many mine slopes, particularly footwalls. Once movement of a slope is occurring, even very low level creep, it is very difficult to implement an effective groundwater monitoring system. The monitoring system has to not only capture all of the key groundwater responses to the environment, but also capture all the responses in the principal defects controlling or influencing stability. As shown in the preceeding sections of the paper these responses will also be subject to change over time. The examples discussed in this paper demonstrate the practical difficulties with this task.

\subsection{Conclusions and recommended good practice}

It should be evident from the preceding discussions that in most footwall situations the key element for successful mining is a very sound pit slope management program. However, the program should be based on the concepts and ideas set out previously because probably the only positive element is time. The failures are not immediate, they take some time to develop and there are abundant warning signs, if the monitoring program is adequate.

In terms of analyses, stability, slope management and preventative factors there are a few key conclusions:

1. Initial calculations of Factors of Safety may assist with checking immediate stability but are probably not useful in the medium to long-term. 
2. In general, it is not possible to stop creep movements occurring in footwall slabs. These creep movements may continue for many years, but ultimately there is a high probability that failure will occur unless positive backfill loading can be achieved.

3. The creep movements will be concentrated on the low strength layers or seams in the floor and over time form a footwall slab or slabs, which may be multi-story.

4. It is then not possible to stop hydromechanical coupling occurring, depending, of course, on the climate, but long thin footwall slabs have very large catchments and even modest rainfall events can become critical.

5. Attempts have been made to control groundwater pressures by horizontal drains and vertical pressure relief wells. However, these will be sheared off and become ineffective. There is also evidence arising to show that in some instances-despite positive early groundwater impactstowards the end of the movement cycle, vertical pressure relief wells, in particular, may actually assist in causing collapse.

6. Re-drilling of wells and drains is an option but this needs careful consideration.

7. Slope height versus slope angle charts, which are used regularly in the industry, are not considered valid for considerations of medium to long-term stability.

8. Prisms are essential and footwall slopes cannot be managed successfully throughout their life using radars alone.

\section{References}

Alonso, EE, Gens, A \& Delahaye, CH 2003, 'Influence of rainfall on deformation and stability of a slope in overconsolidated clay', Hydrogeology Journal, no.11, pp. 174-192.

Beale, G \& Read, JR 2013, 'Guidelines for evaluating water in pit slope stability', CSIRO Publishing, Clayton.

Burland, JB, Longworth, TI \& Moore, JFA 1977, 'A study of ground movement and progressive failure caused by a deep excavation in Oxford Clay', Geotechnique, vol. 27, issue 4, pp. 557-591.

Burman, BC \& Sullivan, TD 1985, 'Dewatering and depressurisation studies for development of the Lochiel open pit mine South Australia', Proceedings of 2nd International Mine Water Congress, Asociacion Nacional de Ingenieros de Minas and International Mine Water Association, Granada, pp. 307-324, https://www.imwa.info/docs/imwa_1985/ IMWA1985_Burman_307.pdf

Carlsson, A \& Olsson, T 1979, 'Hydraulic conductivity and its stress dependency', Proceedings of the Workshop on Low-flow, Low-permeability Measurements in Largely Impermeable Rocks, Organisation for Economic Cooperation and Development and the Nuclear Energy Agency,, Paris, pp. 249-260.

Esaki, T, Du, S, Mitani, Y, Ikusada, K \& Jing, L 1999, 'Development of shear-flow test apparatus and determination of coupled properties for a single rock joint', International Journal of Rock Mechanics Mining Science, vol. 36, pp. 641-650.

Hoek, E \& Brown, ET 2018, 'The Hoek-Brown failure criterion and GSI - 2018 edition', Journal of Rock Mechanics and Geotechnical Engineering, vol. 11, issue 3, pp. 445-463.

Johnston, I 1991, 'Geomechanics and the emergence of soft rock technology', Australian Geomechanics Journal, vol. 21, pp. 3-26.

Londe, P 1987, 'The Malpasset Dam failure', Engineering Geology, vol. 24, pp. 295-329.

Louis, C \& Maini, Y 1970, 'Determination of in-situ hydraulic parameters in jointed rock', Proceedings of the International Congress of Rock Mechanics, vol. 1, International Society of Rock Mechanics, Salzburg, pp. 235-245.

Makurat, A, Barton, N \& Rad, NS 1990, 'Joint conductivity variation due to normal and shear deformation', Rock Joints, Balkema, Rotterdam, pp. 535-540.

National Research Council 1996, Rock Fracture and Fluid Flow, National Academy Press, Washington DC.

Neuzil, CE 2003, 'Hydromechanical coupling in geologic processes', Hydrogeology Journal, vol. 11, pp. 41-83.

Neuzil, CE \& Tracey, JV 1981,' Flow through fractures', Water Resources Research, vol. 17, pp. 191-199.

O'Brien, MD \& Sullivan, TD 1988, 'The Lochiel Trial Pit - design and excavation', Proceedings of the Conference Minerals and Exploration at the Crossroads, Australasian Institute of Mining and Metallurgy, Parkville, pp. 127-133.

Olsson, R 1992, 'Site characterisation and validation - final report: Strippa Project', Swedish Nuclear Fuel Waste Management Co, Stockholm.

Olsson, R \& Barton, N 2001, 'An improved model for hydromechanical coupling during shearing of rock joints', International Journal of Rock Mechanics Mining Science, vol. 38, pp. 317-329.

Rutqvist, J \& Stephansson, O 2003, 'The role of hydromechanical coupling in fractured rock engineering', Hydrogeology Journal, vol. 11, pp. 7-40. 
Rutqvist, J, Tsang, CF, Ekman, D \& Stephannson, O 1997, 'Evaluation of in situ hydromechanical properties of rock fractures at Laxemar in Sweden', Proceedings of the 1st Asian Rock Mechanics Symposium, International Society for Rock Mechanics, Lisbon, pp. 619-624.

Snow, DT 1968, 'Rock fracture spacing, openings and porosities', Journal Soil Mechanics Division, vol. 94, issue 1, pp. $73-91$.

Sullivan, TD 1994, 'Mine slope design - The chances of getting the answer right and the risk of getting it wrong', Proceedings of the Fourth Large Open Pit Mining Conference, Australasian Institute of Mining and Metallurgy, Parkville.

Sullivan, TD 2008, Yallourn Mine Batter Failure Inquiry, Victorian Government Printer, Melbourne.

Sullivan, TD 2007, 'Hydromechanical coupling and pit slope movements', Proceedings of the 2007 International Symposium on Rock Slope Stability in Open Pit Mining and Civil Engineering, Australian Centre for Geomechanics, Perth, pp. 3-43, https://papers.acg.uwa.edu.au/p/708_Sullivan/

Sullivan, TD 2010, 'The geological model', in AL Williams, GM Pinches, CY Chin, TJ McMorran \& Cl Massey (eds), Proceedings of the 11th Congress of International Association for Engineering Geology and the Environment, CRC Press, Boca Raton, pp. 155-170.

Sullivan, TD 2013, 'Global slope performance index', Proceedings of the 2013 International Symposium on Slope Stability in Open Pit Mining and Civil Engineering, Australian Centre for Geomechanics, Perth, pp. 55-80, https://papers.acg.uwa.edu.au/ p/1308_0.4_Sullivan/

Sullivan, TD \& Burman, BC 1985, 'Geological and geotechnical aspects of small basins and their effects on mining', Proceedings of the Asian Mining Conference, Institute of Mining and Metallurgy, London, pp. 321-335.

Sullivan, TD \& Burman, BC 1986, 'The Lochiel Project - a case study of geotechnical engineering studies in a difficult environment', in JT Woodcock (ed.), Proceedings of the 13th Council of Mining and Metallurgical Institutions Congress, Australasian Institute of Mining and Metallurgy, Parkville, pp. 1-10.

Witherspoon, PA, Wang, JSY, Iwai, K \& Gale, JE 1980, 'Validity of the cubic law for fluid flow in deformable rock fracture', Water Resources Research, vol. 16, pp. 1016-1024.

Wladis, D, Jonsson, P \& Wallroth, T 1997, 'Regional characterisation of hydraulic properties of rock using well test data', Technical report, Swedish Nuclear Fuel Waste Management Co, Stockholm.

Wyllie, DC \& Mah, CW 2004, 'Rock Slope Engineering - Civil and Mining', 4th edn, Spon Press, London. 
